\title{
Disorders of Acid-Base Balance
}

\section{Horacio J. Adrogué Nicolaos E. Madias}

M

aintenance of acid-base homeostasis is a vital function of the living organism. Deviations of systemic acidity in either direction can impose adverse consequences and when severe can threaten life itself. A cid-base disorders frequently are encountered in the outpatient and especially in the inpatient setting. Effective management of acid-base disturbances, commonly a challenging task, rests with accurate diagnosis, sound understanding of the underlying pathophysiology and impact on organ function, and familiarity with treatment and attendant complications [1].

Clinical acid-base disorders are conventionally defined from the vantage point of their impact on the carbonic acid-bicarbonate buffer system. This approach is justified by the abundance of this buffer pair in body fluids; its physiologic preeminence; and the validity of the isohydric principle in the living organism, which specifies that all the other buffer systems are in equilibrium with the carbonic acid-bicarbonate buffer pair. Thus, as indicated by the $\mathrm{Henderson}$ equation, $\left[\mathrm{H}^{+}\right]=24 \times \mathrm{PaCO}_{2} /\left[\mathrm{HCO}_{3}^{-}\right]$(the equilibrium relationship of the carbonic acid-bicarbonate system), the hydrogen ion concentration of blood $\left(\left[\mathrm{H}^{+}\right]\right.$, expressed in $\left.\mathrm{nEq} / \mathrm{L}\right)$ at any moment is a function of the prevailing ratio of the arterial carbon dioxide tension $\left(\mathrm{PaCO}_{2}\right.$, expressed in $\mathrm{mm} \mathrm{Hg}$ ) and the plasma bicarbonate concentration ( $\left[\mathrm{HCO}_{3}{ }_{3}\right]$, expressed in $\mathrm{mEq} / \mathrm{L}$ ). As a corollary, changes in systemic acidity can occur only through changes in the values of its two determinants, $\mathrm{PaCO}_{2}$ and the plasma bicarbonate concentration. Those acid-base disorders initiated by a change in $\mathrm{PaCO}_{2}$ are referred to as respiratory disorders; those initiated by a change in plasma bicarbonate concentration are known as metabolic disorders. There are four cardinal acid-base disturbances: respiratory acidosis, respiratory alkalosis, metabolic acidosis, and metabolic alkalosis. Each can be encountered alone, as a simple disorder, or can be a part of a mixeddisorder, defined as the simultaneous presence of two or more simple 
acid-base disturbances. $M$ ixed acid-base disorders are frequently observed in hospitalized patients, especially in the critically ill.

The clinical aspects of the four cardinal acid-base disorders are depicted. For each disorder the following are illustrated: the underlying pathophysiology, secondary adjustments in acid-base equilibrium in response to the initiating disturbance, clinical manifestations, causes, and therapeutic principles.

\section{Respiratory Acidosis}

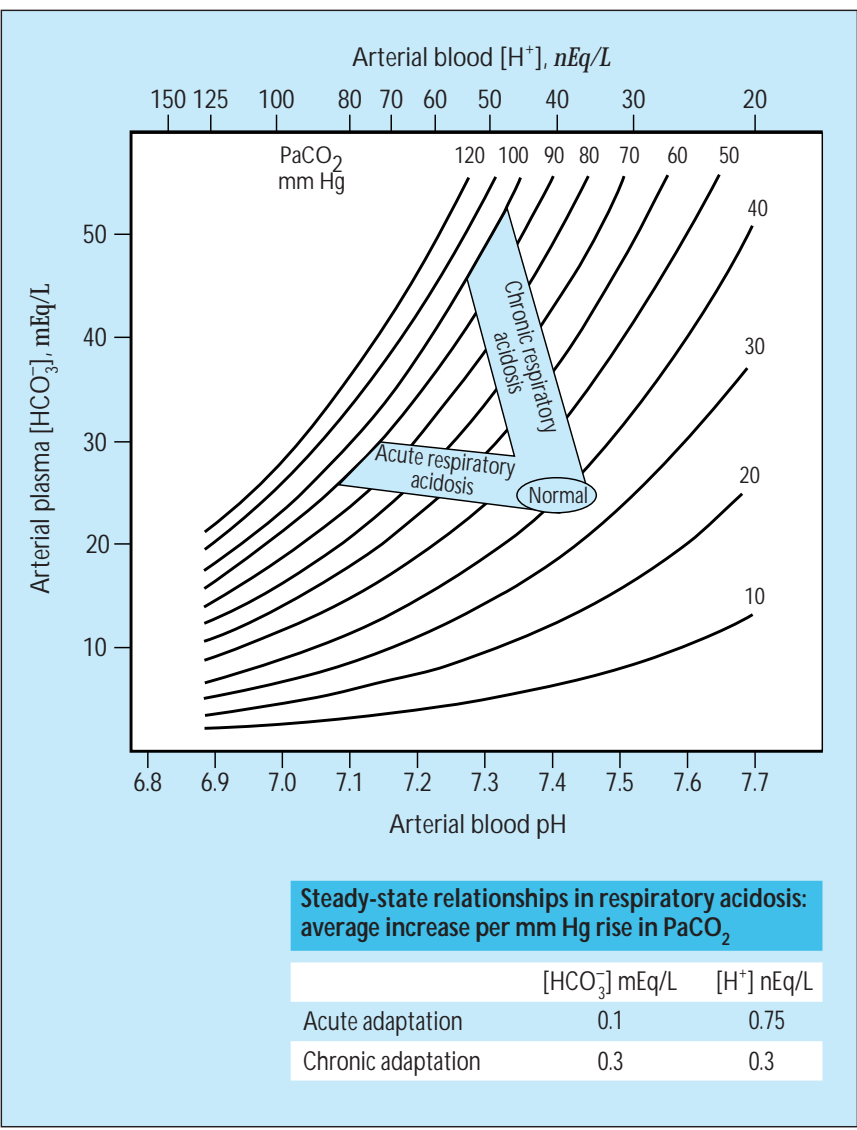

\section{FIGURE 6-1}

Q uantitative aspects of adaptation to respiratory acidosis. Respiratory acidosis, or primary hypercapnia, is the acid-base disturbance initiated by an increase in arterial carbon dioxide tension $\left(\mathrm{PaCO}_{2}\right)$ and entails acidification of body fluids. $\mathrm{H}$ ypercapnia elicits adaptive increments in plasma bicarbonate concentration that should be viewed as an integral part of respiratory acidosis. An immediate increment in plasma bicarbonate occurs in response to hypercapnia. This acute adaptation is complete within 5 to $10 \mathrm{~min}$ utes from the onset of hypercapnia and originates exclusively from acidic titration of the nonbicarbonate buffers of the body (hemoglobin, intracellular proteins and phosphates, and to a lesser extent plasma proteins). W hen hypercapnia is sustained, renal adjustments markedly amplify the secondary increase in plasma bicarbonate, further ameliorating the resulting acidemia. This chronic adaptation requires 3 to 5 days for completion and reflects generation of new bicarbonate by the kidneys as a result of upregulation of renal acidification [2]. Average increases in plasma bicarbonate and hydrogen ion concentrations per $\mathrm{mm} \mathrm{H}$ increase in $\mathrm{PaCO}_{2}$ after completion of the acute or chronic adaptation to respiratory acidosis are shown. Empiric observations on these adaptations have been used for construction of $95 \%$ confidence intervals for graded degrees of acute or chronic respiratory acidosis represented by the areas in color in the acid-base template. The black ellipse near the center of the figure indicates the normal range for the acid-base parameters [3]. N ote that for the same level of $\mathrm{PaCO}_{2}$, the degree of acidemia is considerably lower in chronic respiratory acidosis than it is in acute respiratory acidosis. Assuming a steady state is present, values falling within the areas in color are consistent with but not diagnostic of the corresponding simple disorders. A cid-base values falling outside the areas in color denote the presence of a mixed acid-base disturbance [4]. 


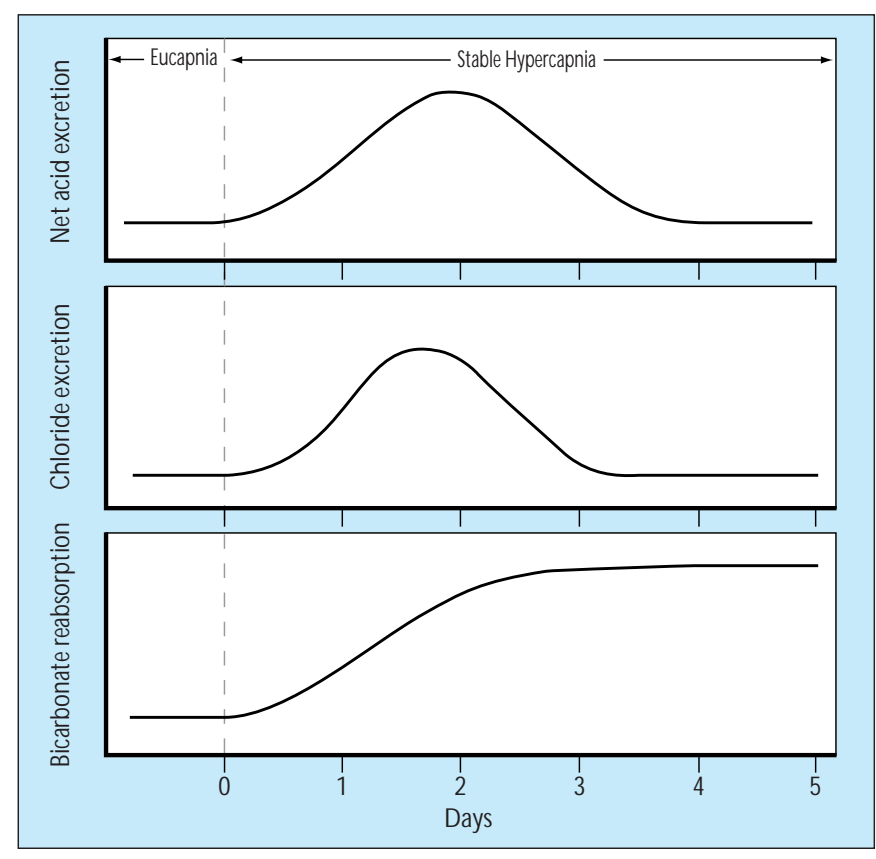

\section{FIGURE 6-2}

Renal acidification response to chronic hypercapnia. Sustained hypercapnia entails a persistent increase in the secretory rate of the renal tubule for hydrogen ions $\left(\mathrm{H}^{+}\right)$and a persistent decrease in the reabsorption rate of chloride ions $\left(\mathrm{Cl}^{-}\right)$. Consequently, net acid excretion (largely in the form of ammonium) transiently exceeds endogenous acid production, leading to generation of new bicarbonate ions $\left(\mathrm{HCO}_{3}^{-}\right)$for the body fluids. Conservation of these new bicarbonate ions is ensured by the gradual augmentation in the rate of renal bicarbonate reabsorption, itself a reflection of the hypercapnia-induced increase in the hydrogen ion secretory rate. A new steady state emerges when two things occur: the augmented filtered load of bicarbonate is precisely balanced by the accelerated rate of bicarbonate reabsorption and net acid excretion returns to the level required to offset daily endogenous acid production. The transient increase in net acid excretion is accompanied by a transient increase in chloride excretion. Thus, the resultant ammonium chloride $\left(\mathrm{NH}_{4} \mathrm{Cl}\right.$ ) loss generates the hypochloremic hyperbicarbonatemia characteristic of chronic respiratory acidosis. H ypochloremia is sustained by the persistently depressed chloride reabsorption rate. The specific cellular mechanisms mediating the renal acidification response to chronic hypercapnia are under active investigation. Available evidence supports a parallel increase in the rates of the luminal sodium ionhydrogen ion $\left(\mathrm{N} \mathrm{a}^{+}-\mathrm{H}^{+}\right)$exchanger and the basolateral $\mathrm{Na}^{+}-3 \mathrm{HCO}_{3}^{-}$ cotransporter in the proximal tubule. However, the nature of these adaptations remains unknown [5]. The quantity of the $\mathrm{H}$ +-adenosine triphosphatase (ATPase) pumps does not change in either cortex or medulla. However, hypercapnia induces exocytotic insertion of $\mathrm{H}^{+}$ ATPase-containing subapical vesicles to the luminal membrane of proximal tubule cells as well as type A intercalated cells of the cortical and medullary collecting ducts. $\mathrm{N} \mathrm{ew} \mathrm{H}^{+}$-ATPase pumps thereby are recruited to the luminal membrane for augmented acidification $[6,7]$. Furthermore, chronic hypercapnia increases the steady-state abundance of mRNA coding for the basolateral $\mathrm{Cl}-\mathrm{HCO}_{3}^{-}$exchanger (band 3 protein) of type $\mathrm{A}$ intercalated cells in rat renal cortex and medulla, likely indicating increased band 3 protein levels and therefore augmented basolateral anion exchanger activity [8].

\section{SIGNSAND SYMPTOMS OF RESPIRATORY ACIDOSIS}

\begin{tabular}{lll}
\hline \hline Central Nervous System & Respiratory System & Cardiovascular System \\
\hline Mild to moderate hypercapnia & Breathlessness & Mild to moderate hypercapnia \\
Cerebral vasodilation & Central and peripheral cyanosis & Warm and flushed skin \\
Increased intracranial pressure & (especially when breathing & Bounding pulse \\
Headache & room air) & Well maintained cardiac \\
Confusion & Pulmonary hypertension & output and blood pressure \\
Combativeness & & Diaphoresis \\
Hallucinations & & Severe hypercapnia \\
Transient psychosis & Cor pulmonale \\
Myoclonic jerks & Decreased cardiac output \\
Flapping tremor & Systemic hypotension \\
Severe hypercapnia & Cardiac arrhythmias \\
Manifestations of pseudotumor cerebri & Prerenal azotemia \\
Stupor & Peripheral edema \\
Coma & \\
Constricted pupils & \\
Depressed tendon reflexes & \\
Extensor plantar response & \\
Seizures & \\
Papilledema & \\
\hline \hline
\end{tabular}

\section{FIGURE 6-3}

Signs and symptoms of respiratory acidosis. The effects of respiratory acidosis on the central nervous system are collectively known as hypercapnic encephalopathy. Factors responsible for its development include the magnitude and time course of the hypercapnia, severity of the acidemia, and degree of attendant hypoxemia. Progressive narcosis and coma may occur in patients receiving uncontrolled oxygen therapy in whom levels of arterial carbon dioxide tension $\left(\mathrm{PaCO}_{2}\right)$ may reach or exceed $100 \mathrm{~mm} \mathrm{H} \mathrm{g}$. The hemodynamic consequences of carbon dioxide retention reflect several mechanisms, including direct impairment of myocardial contractility, systemic vasodilation caused by direct relaxation of vascular smooth muscle, sympathetic stimulation, and acidosis-induced blunting of receptor responsiveness to catecholamines. The net effect is dilation of systemic vessels, including the cerebral circulation; whereas vasoconstriction might develop in the pulmonary and renal circulations. Salt and water retention commonly occur in chronic hypercapnia, especially in the presence of cor pulmonale. M echanisms at play include hypercapnia-induced stimulation of the renin-angiotensin-aldosterone axis and the sympathetic nervous system, elevated levels of cortisol and antidiuretic hormone, and increased renal vascular resistance. of course, coexisting heart failure amplifies most of these mechanisms [1,2]. 


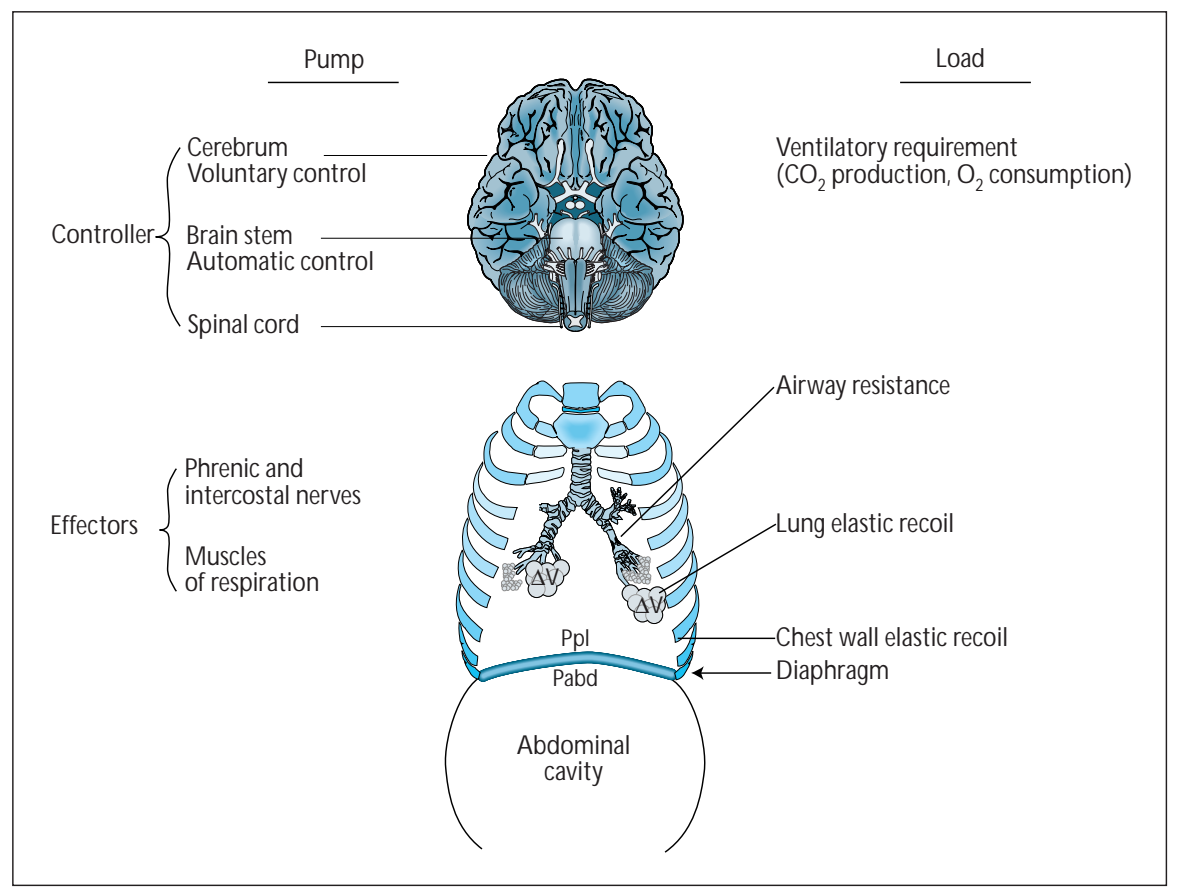

\section{FIGURE 6-4}

$M$ ain components of the ventilatory system. The ventilatory system is responsible for maintaining the arterial carbon dioxide tension $\left(\mathrm{PaCO}_{2}\right)$ within normal limits by adjusting minute ventilation $(\dot{v})$ to match the rate of carbon dioxide production. The main elements of ventilation are the respiratory pump, which generates a pressure gradient responsible for air flow, and the loads that oppose such action. The machinery of the respiratory pump includes the cerebrum, brain stem, spinal cord, phrenic and intercostal nerves, and the muscles of respiration. Inspiratory muscle contraction lowers pleural pressure $(\mathrm{Ppl})$ thereby inflating the lungs $(\Delta \mathrm{V})$. The diaphragm, the most important inspiratory muscle, moves downward as a piston at the floor of the thorax, raising abdominal pressure (Pabd). The inspiratory decrease in Ppl by the respiratory pump must be sufficient to counterbalance the opposing effect of the combined loads, including the airway flow resistance, and the elastic recoil of the lungs and chest wall. The ventilatory requirement influences the load by altering the frequency and depth of the ventilatory cycle. The strength of the respiratory pump is evaluated by the pressure generated ( $\Delta \mathrm{P}=\mathrm{Ppl}-\mathrm{Pabd})$. 


\section{DETERMINANTSAND CAUSES OF CARBON DIOXIDE RETENTION}

\begin{tabular}{|c|c|c|c|}
\hline \multicolumn{2}{|c|}{ Respiratory Pump } & \multicolumn{2}{|l|}{ Load } \\
\hline $\begin{array}{l}\text { Depressed Central Drive } \\
\text { Acute } \\
\text { General anesthesia } \\
\text { Sedative overdose } \\
\text { Head trauma } \\
\text { Cerebrovascular accident } \\
\text { Central sleep apnea } \\
\text { Cerebral edema } \\
\text { Brain tumor } \\
\text { Encephalitis } \\
\text { Brainstem lesion } \\
\text { Chronic } \\
\text { Sedative overdose } \\
\text { Methadone or heroin addiction } \\
\text { Sleep disordered breathing } \\
\text { Brain tumor } \\
\text { Bulbar poliomyelitis } \\
\text { Hypothyroidism }\end{array}$ & $\begin{array}{l}\text { Abnormal Neuromuscular Transmission } \\
\text { Acute } \\
\text { High spinal cord injury } \\
\text { Guillain-Barré syndrome } \\
\text { Status epilepticus } \\
\text { Botulism } \\
\text { Tetanus } \\
\text { Crisis in myasthenia gravis } \\
\text { Hypokalemic myopathy } \\
\text { Familial periodic paralysis } \\
\text { Drugs or toxic agents eg, curare, } \\
\text { succinylcholine, aminoglycosides, } \\
\text { organophosphorus } \\
\text { Chronic } \\
\text { Poliomyelitis } \\
\text { Multiple sclerosis } \\
\text { Muscular dystrophy } \\
\text { Amyotrophic lateral sclerosis } \\
\text { Diaphragmatic paralysis } \\
\text { Myopathic disease eg, polymyositis } \\
\text { Muscle Dysfunction } \\
\text { Acute } \\
\text { Fatigue } \\
\text { Hyperkalemia } \\
\text { Hypokalemia } \\
\text { Hypoperfusion state } \\
\text { Hypoxemia } \\
\text { Malnutrition } \\
\text { Chronic } \\
\text { Myopathic disease eg, polymyositis }\end{array}$ & $\begin{array}{l}\text { Increased Ventilatory Demand } \\
\text { High carbohydrate diet } \\
\text { Sorbent-regenerative hemodialysis } \\
\text { Pulmonary thromboembolism } \\
\text { Fat, air pulmonary embolism } \\
\text { Sepsis } \\
\text { Hypovolemia } \\
\text { Augmented Airway Flow Resistance } \\
\text { Acute } \\
\text { Upper airway obstruction } \\
\text { Coma-induced hypopharyngeal obstruction } \\
\text { Aspiration of foreign body or vomitus } \\
\text { Laryngospasm } \\
\text { Angioedema } \\
\text { Obstructive sleep apnea } \\
\text { Inadequate laryngeal intubation } \\
\text { Laryngeal obstruction after intubation } \\
\text { Lower airway obstruction } \\
\text { Generalized bronchospasm } \\
\text { Airway edema and secretions } \\
\text { Severe episode of spasmodic asthma } \\
\text { Bronchiolitis of infants and adults } \\
\text { Chronic } \\
\text { Upper airway obstruction } \\
\text { Tonsillar and peritonsillar hypertrophy } \\
\text { Paralysis of vocal cords } \\
\text { Tumor of the cords or larynx } \\
\text { Airway stenosis after prolonged intubation } \\
\text { Thymoma, aortic aneurysm } \\
\text { Lower airway obstruction } \\
\text { Airway scarring } \\
\text { Chronic obstructive lung disease eg, bronchitis, } \\
\text { bronchiolitis, bronchiectasis, emphysema }\end{array}$ & $\begin{array}{l}\text { Lung Stiffness } \\
\text { Acute } \\
\text { Severe bilateral pneumonia } \\
\text { or bronchopneumonia } \\
\text { Acute respiratory } \\
\text { distress syndrome } \\
\text { Severe pulmonary edema } \\
\text { Atelectasis } \\
\text { Chronic } \\
\text { Severe chronic pneumonitis } \\
\text { Diffuse infiltrative disease eg, } \\
\text { alveolar proteinosis } \\
\text { Interstitial fibrosis } \\
\text { Chest Wall Stiffness } \\
\text { Acute } \\
\text { Rib fractures with flail chest } \\
\text { Pneumothorax } \\
\text { Hemothorax } \\
\text { Abdominal distention } \\
\text { Ascites } \\
\text { Peritoneal dialysis } \\
\text { Chronic } \\
\text { Kyphoscoliosis, spinal arthritis } \\
\text { Obesity } \\
\text { Fibrothorax } \\
\text { Hydrothorax } \\
\text { Chest wall tumor }\end{array}$ \\
\hline
\end{tabular}

\section{FIGURE 6-5}

D eterminants and causes of carbon dioxide retention. When the respiratory pump is unable to balance the opposing load, respiratory acidosis develops. D ecreases in respiratory pump strength, increases in load, or a combination of the two, can result in carbon dioxide retention. Respiratory pump failure can occur because of depressed central drive, abnormal neuromuscular transmission, or respiratory muscle dysfunction. A higher load can be caused by increased ventilatory demand, augmented airway flow resistance, and stiffness of the lungs or chest wall. In most cases, causes of the various determinants of carbon dioxide retention, and thus respiratory acidosis, are categorized into acute and chronic subgroups, taking into consideration their usual mode of onset and duration [2]. 


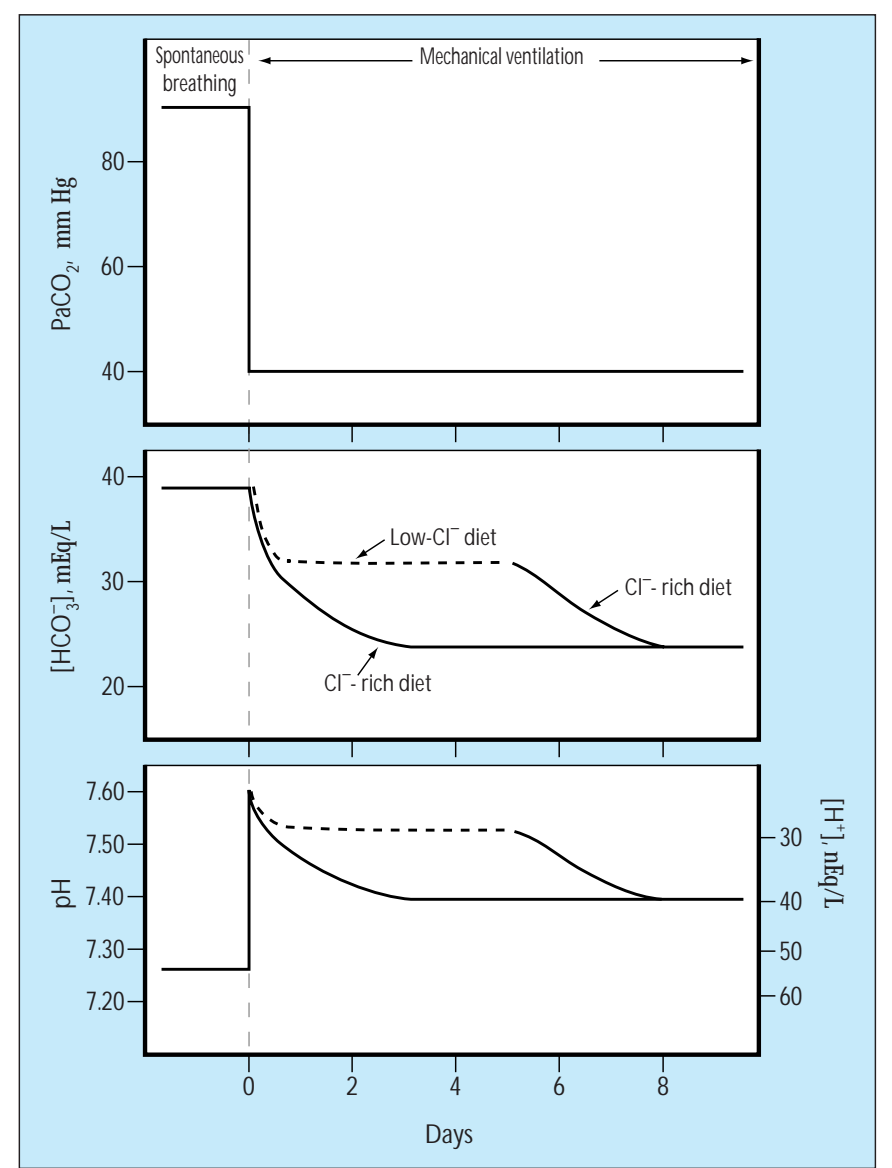

\section{FIGURE 6-6}

Posthypercapnic metabolic alkalosis. Development of posthypercapnic metabolic alkalosis is shown after abrupt normalization of the arterial carbon dioxide tension $\left(\mathrm{PaCO}_{2}\right)$ by way of mechanical ventilation in a 70-year-old man with respiratory decompensation who has chronic obstructive pulmonary disease and chronic hypercapnia. The acute decrease in plasma bicarbonate concentration ([ $\left.\mathrm{HCO}_{3}^{-}\right]$) over the first few minutes after the decrease in $\mathrm{PaCO}_{2}$ originates from alkaline titration of the nonbicarbonate buffers of the body. When a diet rich in chloride $\left(\mathrm{Cl}^{-}\right)$is provided, the excess bicarbonate is excreted by the kidneys over the next 2 to 3 days, and acidbase equilibrium is normalized. In contrast, a low-chloride diet sustains the hyperbicarbonatemia and perpetuates the posthypercapnic metabolic alkalosis. A brupt correction of severe hypercapnia by way of mechanical ventilation generally is not recommended. R ather, gradual return toward the patient's baseline $\mathrm{PaCO}_{2}$ level should be pursued $[1,2]$. $\left[\mathrm{H}^{+}\right]$-hydrogen ion concentration.

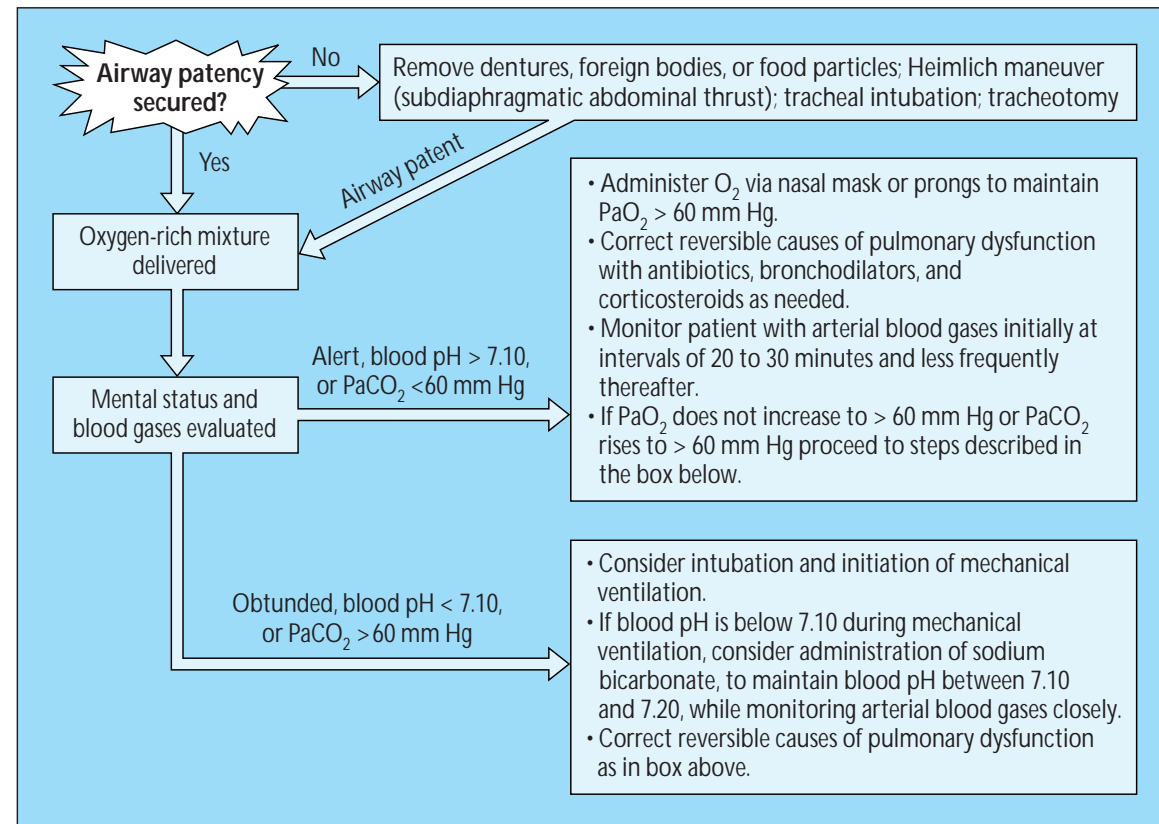

\section{FIGURE 6-7}

Acute respiratory acidosis management. Securing airway patency and delivering an oxygen-rich mixture are critical initial steps in management. Subsequent measures must be directed at identifying and correcting the underlying cause, whenever possible $[1,9]$. $\mathrm{PaCO}_{2}$-arterial carbon dioxide tension. 


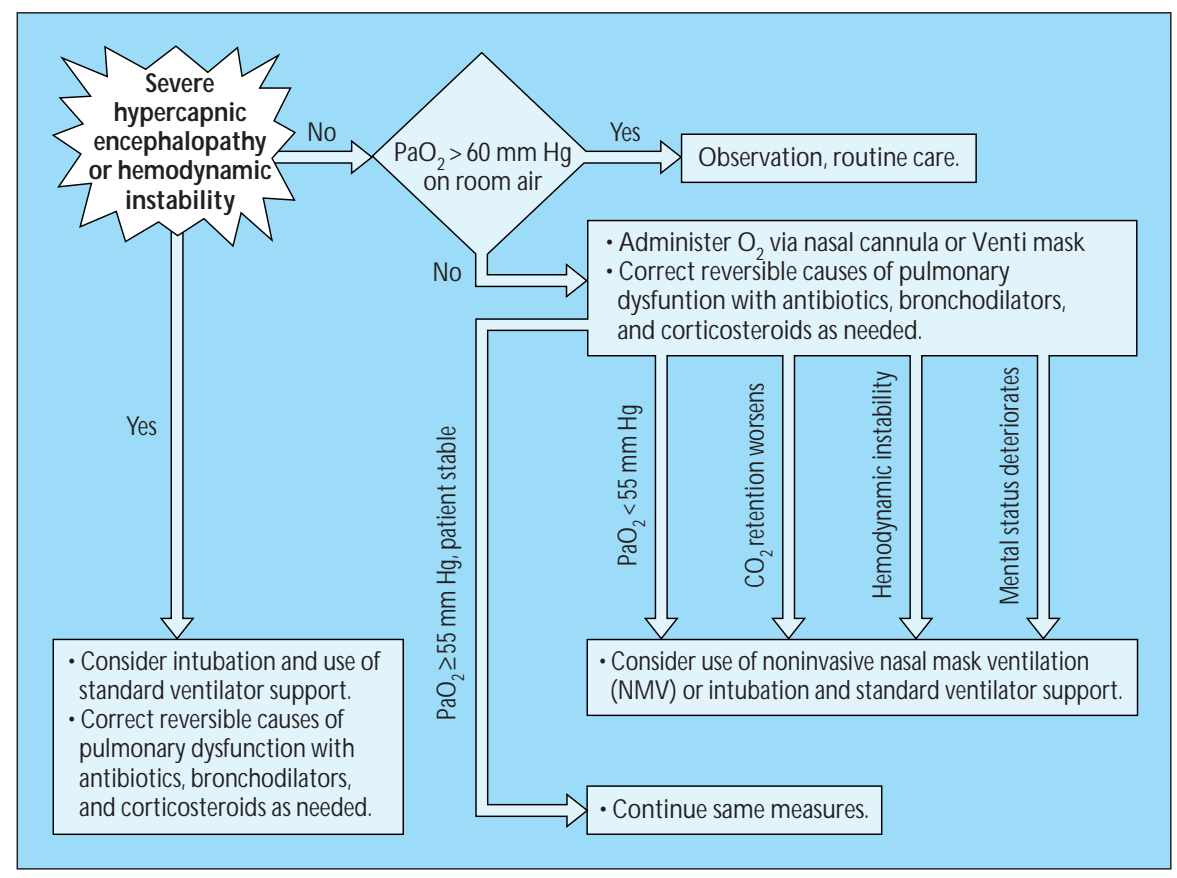

\section{FIGURE 6-8}

Chronic respiratory acidosis management. Therapeutic measures are guided by the presence or absence of severe hypercapnic encephalopathy or hemodynamic instability. An aggressive approach that favors the early use of ventilator assistance is most appropriate for patients with acute respiratory acidosis. In contrast, a more conservative approach is advisable in patients with chronic hypercapnia because of the great difficulty often encountered in weaning these patients from ventilators. As a rule, the lowest possible inspired fraction of oxygen that achieves adequate oxygenation $\left(\mathrm{PaO}_{2}\right.$ on the order of $\left.60 \mathrm{~mm} \mathrm{Hg}\right)$ is used. Contrary to acute respiratory acidosis, the underlying cause of chronic respiratory acidosis only rarely can be resolved $[1,9]$.

\section{Respiratory Alkalosis}

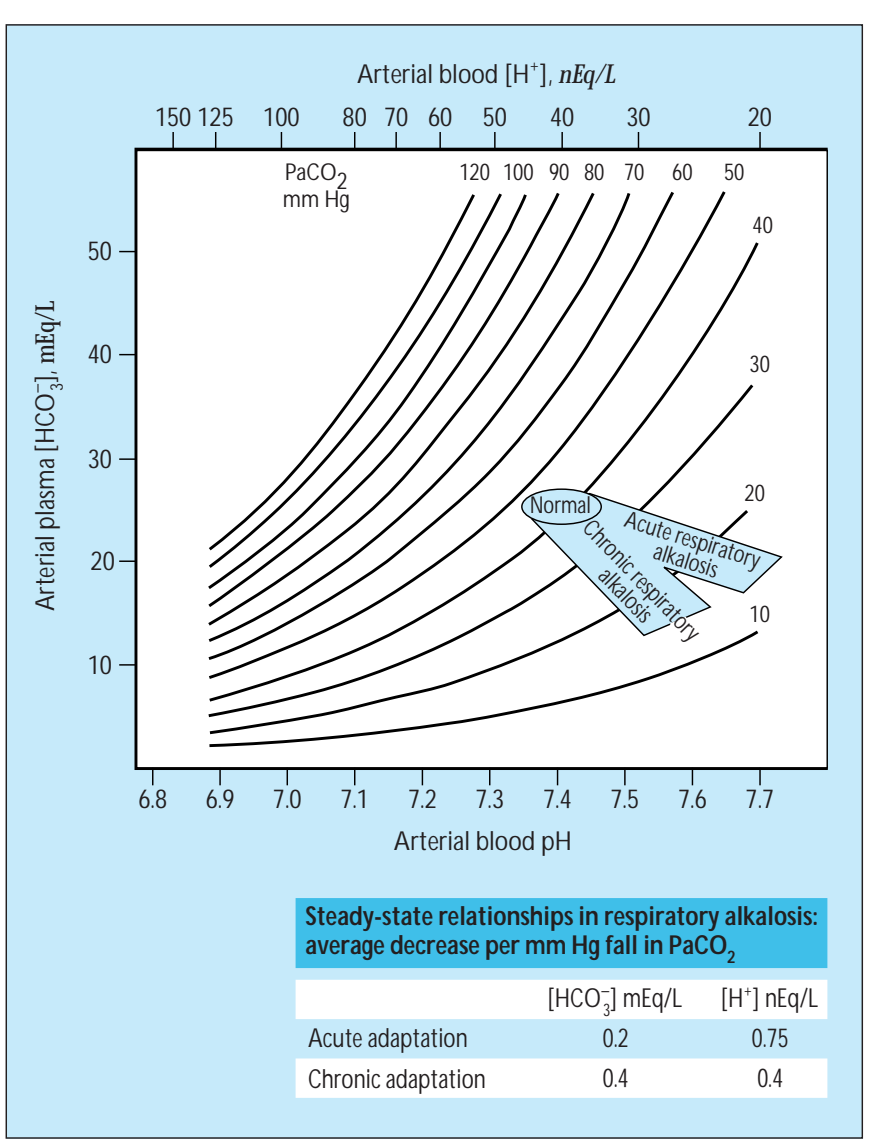

\section{FIGURE 6-9}

Adaptation to respiratory alkalosis. Respiratory alkalosis, or primary hypocapnia, is the acid-base disturbance initiated by a decrease in arterial carbon dioxide tension $\left(\mathrm{PaCO}_{2}\right)$ and entails alkalinization of body fluids. H ypocapnia elicits adaptive decrements in plasma bicarbonate concentration that should be viewed as an integral part of respiratory alkalosis. An immediate decrement in plasma bicarbonate occurs in response to hypocapnia. This acute adaptation is complete within 5 to 10 minutes from the onset of hypocapnia and is accounted for principally by alkaline titration of the nonbicarbonate buffers of the body. To a lesser extent, this acute adaptation reflects increased production of organic acids, notably lactic acid. When hypocapnia is sustained, renal adjustments cause an additional decrease in plasma bicarbonate, further ameliorating the resulting alkalemia. This chronic adaptation requires 2 to 3 days for completion and reflects retention of hydrogen ions by the kidneys as a result of downregulation of renal acidification $[2,10]$. Shown are the average decreases in plasma bicarbonate and hydrogen ion concentrations per $\mathrm{mm} \mathrm{H} g$ decrease in $\mathrm{PaCO}_{2}$ after completion of the acute or chronic adaptation to respiratory alkalosis. Empiric observations on these adaptations have been used for constructing 95\% confidence intervals for graded degrees of acute or chronic respiratory alkalosis, which are represented by the areas in color in the acid-base template. The black ellipse near the center of the figure indicates the normal range for the acid-base parameters. $\mathrm{N}$ ote that for the same level of $\mathrm{PaCO}_{2}$, the degree of alkalemia is considerably lower in chronic than it is in acute respiratory alkalosis. Assuming that a steady state is present, values falling within the areas in color are consistent with but not diagnostic of the corresponding simple disorders. A cid-base values falling outside the areas in color denote the presence of a mixed acid-base disturbance [4]. 


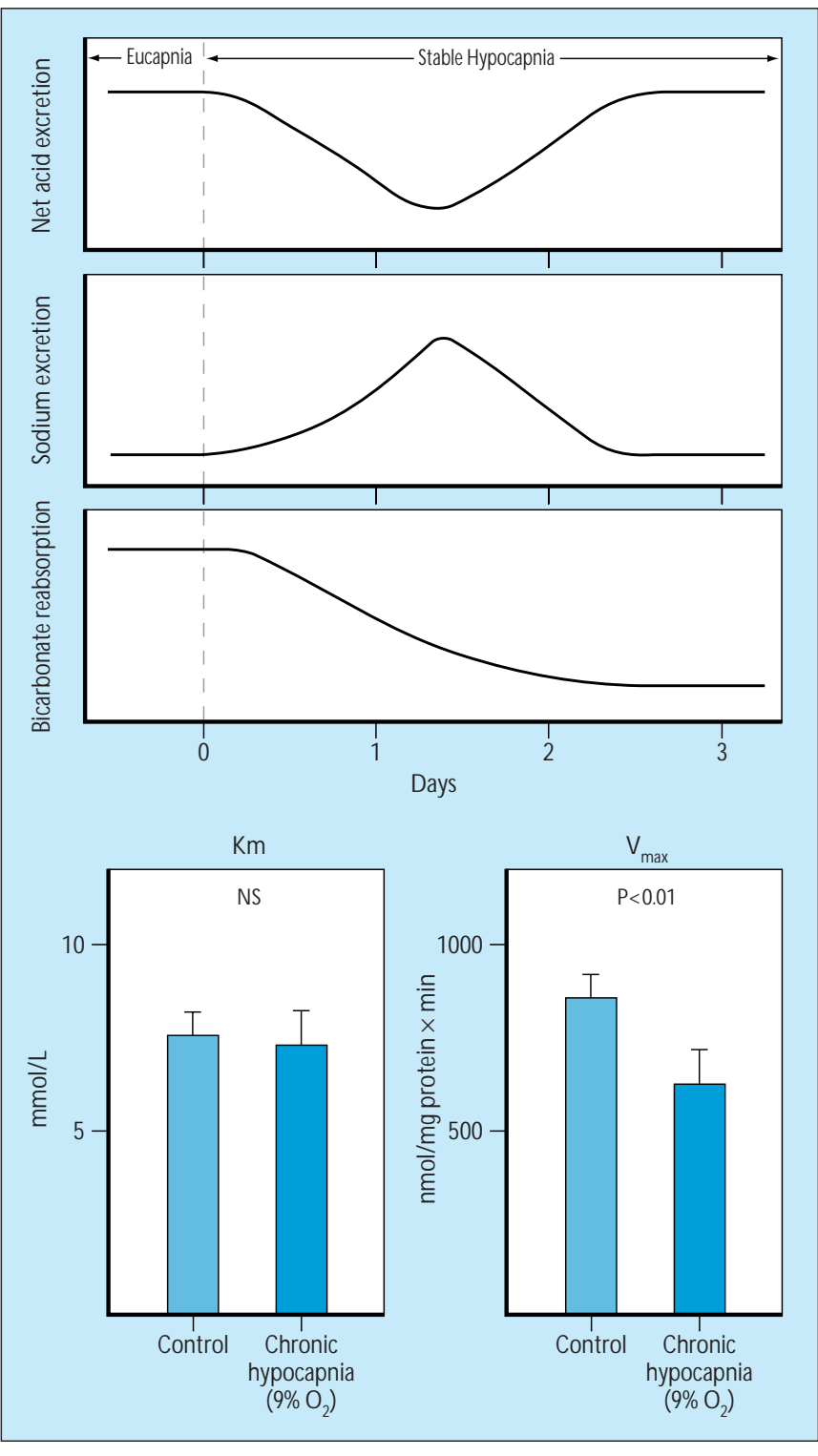

\section{FIGURE 6-10}

Renal acidification response to chronic hypocapnia. A, Sustained hypocapnia entails a persistent decrease in the renal tubular secretory rate of hydrogen ions and a persistent increase in the chloride reabsorption rate. As a result, transient suppression of net acid excretion occurs. This suppression is largely manifested by a decrease in ammonium excretion and, early on, by an increase in bicarbonate excretion. The transient discrepancy between net acid excretion and endogenous acid production, in turn, leads to positive hydrogen ion balance and a reduction in the bicarbonate stores of the body. $M$ aintenance of the resulting hypobicarbonatemia is ensured by the gradual suppression in the rate of renal bicarbonate reabsorption. This suppression itself is a reflection of the hypocapnia-induced decrease in the hydrogen ion secretory rate. A new steady state emerges when two things occur: the reduced filtered load of bicarbonate is precisely balanced by the dampened rate of bicarbonate reabsorption and net acid excretion returns to the level required to offset daily endogenous acid production. The transient retention of acid during sustained hypocapnia is normally accompanied by a loss of sodium in the urine (and not by a retention of chloride as analogy with chronic respiratory acidosis would dictate). The resulting extracellular fluid loss is responsible for the hyperchloremia that typically accompanies chronic respiratory alkalosis. $\mathrm{H}$ yperchloremia is sustained by the persistently enhanced chloride reabsorption rate. If dietary sodium is restricted, acid retention is achieved in the company of increased potassium excretion. The specific cellular mechanisms mediating the renal acidification response to chronic hypocapnia are under investigation. Available evidence indicates a parallel decrease in the rates of the luminal sodium ion-hydrogen ion $\left(\mathrm{N} \mathrm{a}^{+}-\mathrm{H}^{+}\right)$exchanger and the basolateral sodium ion-3 bicarbonate ion $\left(\mathrm{N} \mathrm{a}^{+}-3 \mathrm{H} \mathrm{CO}_{3}^{-}\right)$cotransporter in the proximal tubule. This parallel decrease reflects a decrease in the maximum velocity $\left(\mathrm{V}_{\max }\right)$ of each transporter but no change in the substrate concentration at halfmaximal velocity $\left(\mathrm{K}_{\mathrm{m}}\right)$ for sodium (as shown in $\mathbf{B}$ for the $\mathrm{Na}^{+}-\mathrm{H}^{+}$ exchanger in rabbit renal cortical brush-border membrane vesicles) [11]. M oreover, hypocapnia induces endocytotic retrieval of $\mathrm{H}^{+}$ adenosine triphosphatase (ATPase) pumps from the luminal membrane of the proximal tubule cells as well as type A intercalated cells of the cortical and medullary collecting ducts. It remains unknown whether chronic hypocapnia alters the quantity of the $\mathrm{H}^{+}$-AT Pase pumps as well as the kinetics or quantity of other acidification transporters in the renal cortex or medulla [6]. N S- not significant. (B, From Hilden and coworkers [11]; with permission.)

\section{SIGNS AND SYMPTOMS OF RESPIRATORY ALKALOSIS}

\begin{tabular}{|c|c|c|}
\hline Central Nervous System & Cardiovascular System & Neuromuscular System \\
\hline $\begin{array}{l}\text { Cerebral vasoconstriction } \\
\text { Reduction in intracranial pressure } \\
\text { Light-headedness } \\
\text { Confusion } \\
\text { Increased deep tendon reflexes } \\
\text { Generalized seizures }\end{array}$ & $\begin{array}{l}\text { Chest oppression } \\
\text { Angina pectoris } \\
\text { Ischemic electrocardiographic changes } \\
\text { Normal or decreased blood pressure } \\
\text { Cardiac arrhythmias } \\
\text { Peripheral vasoconstriction }\end{array}$ & $\begin{array}{l}\text { Numbness and paresthesias } \\
\text { of the extremities } \\
\text { Circumoral numbness } \\
\text { Laryngeal spasm } \\
\text { Manifestations of tetany } \\
\text { Muscle cramps } \\
\text { Carpopedal spasm } \\
\text { Trousseau's sign } \\
\text { Chvostek's sign }\end{array}$ \\
\hline
\end{tabular}

\section{FIGURE 6-11}

Signs and symptoms of respiratory alkalosis. The manifestations of primary hypocapnia frequently occur in the acute phase, but seldom are evident in chronic respiratory alkalosis. Several mechanisms mediate these clinical manifestations, including cerebral hypoperfusion, alkalemia, hypocalcemia, hypokalemia, and decreased release of oxygen to the tissues by hemoglobin. The cardiovascular effects of respiratory alkalosis are more prominent in patients undergoing mechanical ventilation and those with ischemic heart disease [2]. 


\section{CAUSES OF RESPIRATORY ALKALOSIS}

\begin{tabular}{lllll}
\hline \hline & Central Nervous & & & \\
Hypoxemia or Tissue Hypoxia & System Stimulation & Drugs or Hormones & Stimulation of Chest Receptors & Miscellaneous \\
\hline Decreased inspired oxygen tension & Voluntary & Nikethamide, ethamivan & Pneumonia & Pregnancy \\
High altitude & Pain & Doxapram & Asthma & Gram-positive septicemia \\
Bacterial or viral pneumonia & Anxiety syndrome- & Xanthines & Pneumothorax & Gram-negative septicemia \\
Aspiration of food, foreign object, & hyperventilation syndrome & Salicylates & Hemothorax & Hepatic failure \\
or vomitus & Psychosis & Catecholamines & Flail chest & Mechanical hyperventilation \\
Laryngospasm & Fever & Angiotensin II & Acute respiratory distress syndrome & Heat exposure \\
Drowning & Subarachnoid hemorrhage & Vasopressor agents & Cardiogenic and noncardiogenic & Recovery from metabolic acidosis \\
Cyanotic heart disease & Cerebrovascular accident & Progesterone & pulmonary edema & \\
Severe anemia & Meningoencephalitis & Medroxyprogesterone & Pulmonary embolism & Pulmonary fibrosis \\
Left shift deviation of & Tumor & Dinitrophenol & & \\
oxyhemoglobin curve & Trauma & Nicotine & & \\
Hypotension & & & & \\
Severe circulatory failure & & & \\
Pulmonary edema & & & & \\
& & & & \\
\hline \hline
\end{tabular}

\section{FIGURE 6-12}

Respiratory alkalosis is the most frequent acid-base disorder encountered because it occurs in normal pregnancy and highaltitude residence. Pathologic causes of respiratory alkalosis include various hypoxemic conditions, pulmonary disorders, central nervous system diseases, pharmacologic or hormonal stimulation of ventilation, hepatic failure, sepsis, the anxiety-hyperventilation syndrome, and other entities. M ost of these causes are associated with the abrupt occurrence of hypocapnia; however, in many instances, the process might be sufficiently prolonged

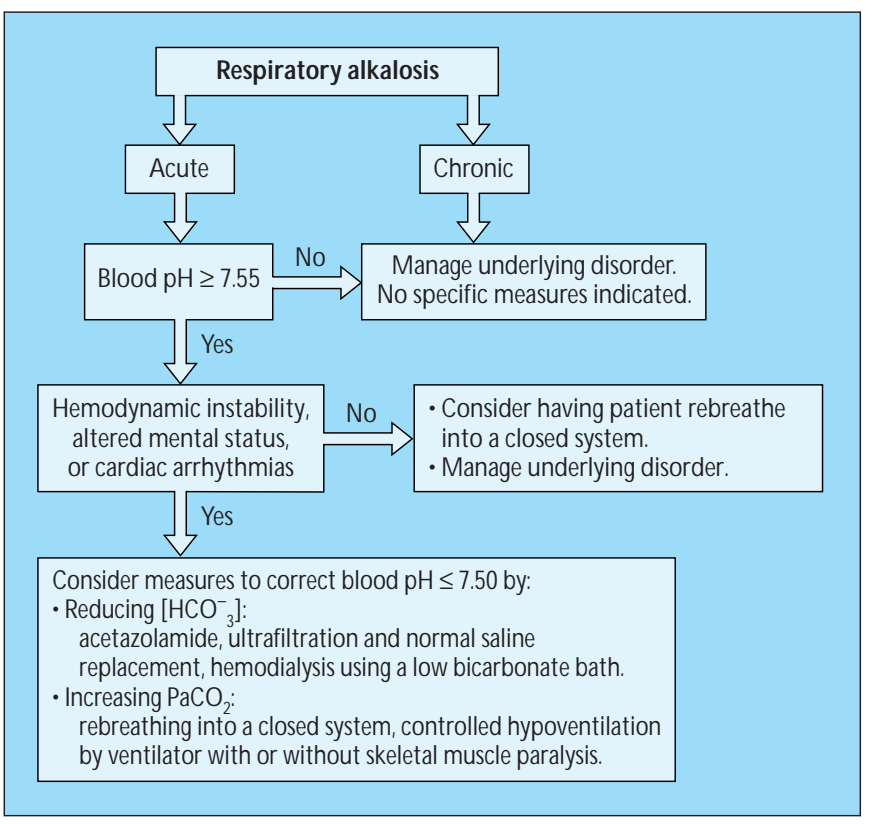

to permit full chronic adaptation to occur. Consequently, no attempt has been made to separate these conditions into acute and chronic categories. Some of the major causes of respiratory alkalosis are benign, whereas others are life-threatening. Primary hypocapnia is particularly common among the critically ill, occurring either as the simple disorder or as a component of mixed disturbances. Its presence constitutes an ominous prognostic sign, with mortality increasing in direct proportion to the severity of the hypocapnia [2].

\section{FIGURE 6-13}

Respiratory alkalosis management. Because chronic respiratory alkalosis poses a low risk to health and produces few or no symptoms, measures for treating the acid-base disorder itself are not required. In contrast, severe alkalemia caused by acute primary hypocapnia requires corrective measures that depend on whether serious clinical manifestations are present. Such measures can be directed at reducing plasma bicarbonate concentration ([ $\left.\left.\mathrm{HCO}_{3}^{-}\right]\right)$, increasing the arterial carbon dioxide tension $\left(\mathrm{PaCO}_{2}\right)$, or both. Even if the baseline plasma bicarbonate is moderately decreased, reducing it further can be particularly rewarding in this setting. In addition, this maneuver combines effectiveness with relatively little risk [1,2]. 


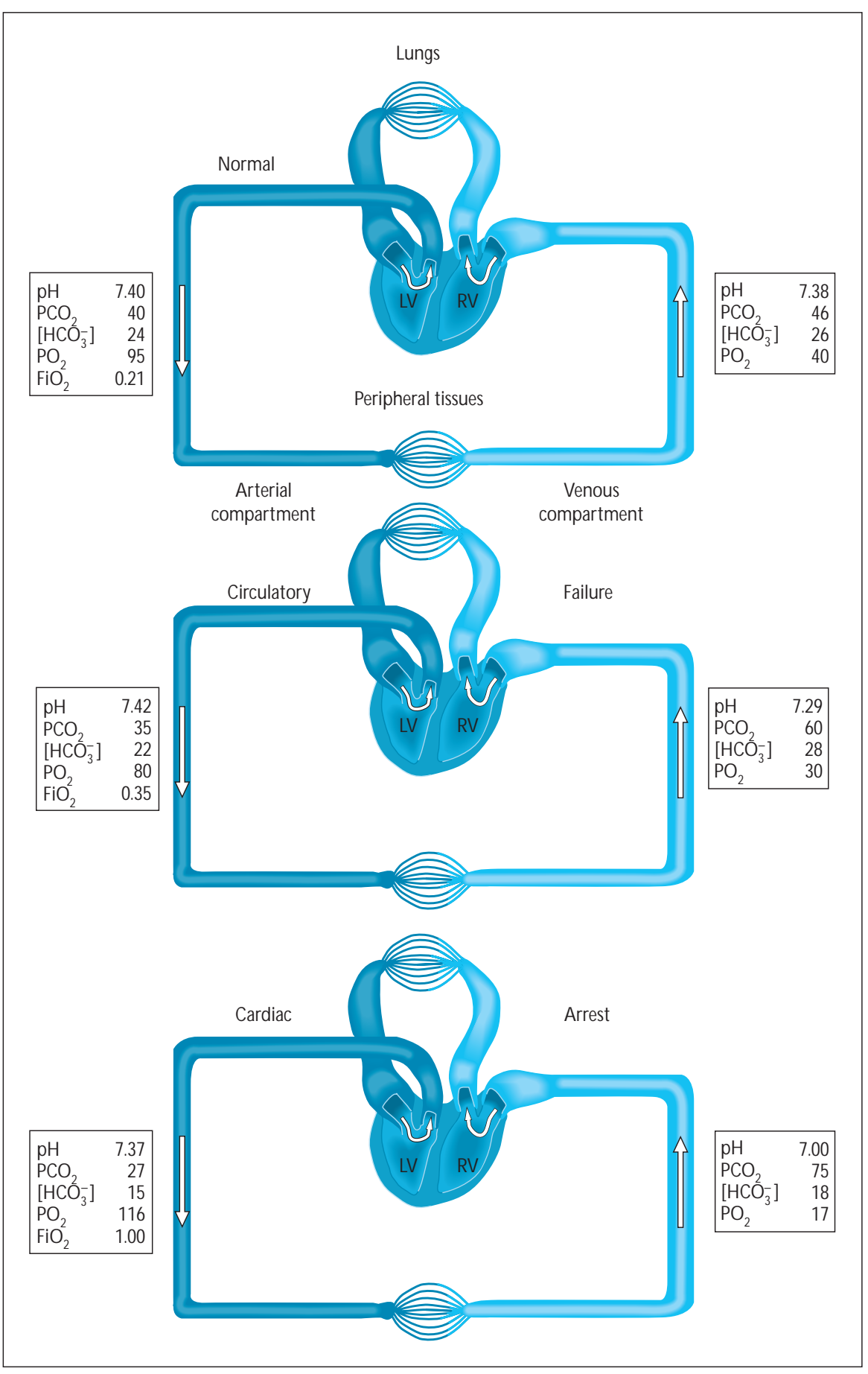

\section{FIGURE 6-14}

Pseudorespiratory al kalosis. This entity develops in patients with profound depression of cardiac function and pulmonary perfusion but relative preservation of alveolar ventilation. Patients include those with advanced circulatory failure and those undergoing cardiopulmonary resuscitation. The severely reduced pulmonary blood flow limits the amount of carbon dioxide delivered to the lungs for excretion, thereby increasing the venous carbon dioxide tension $\left(\mathrm{PCO}_{2}\right)$. In contrast, the increased ventilation-to-perfusion ratio causes a larger than normal removal of carbon dioxide per unit of blood traversing the pulmonary circulation, thereby giving rise to arterial hypocapnia $[12,13]$. N ote a progressive widening of the arteriovenous difference in $\mathrm{pH}$ and $\mathrm{PCO}_{2}$ in the two settings of cardiac dysfunction. The hypobicarbonatemia in the setting of cardiac arrest represents a complicating element of lactic acidosis. Despite the presence of arterial hypocapnia, pseudorespiratory al kalosis represents a special case of respiratory acidosis, as absolute carbon dioxide excretion is decreased and body carbon dioxide balance is positive. Furthermore, the extreme oxygen deprivation prevailing in the tissues might be completely disguised by the reasonably preserved arterial oxygen values. A ppropriate monitoring of acid-base composition and oxygenation in patients with advanced cardiac dysfunction requires mixed (or central) venous blood sampling in addition to arterial blood sampling. $M$ anagement of pseudorespiratory al kalosis must be directed at optimizing systemic hemodynamics [1,13]. 


\section{Metabolic Acidosis}

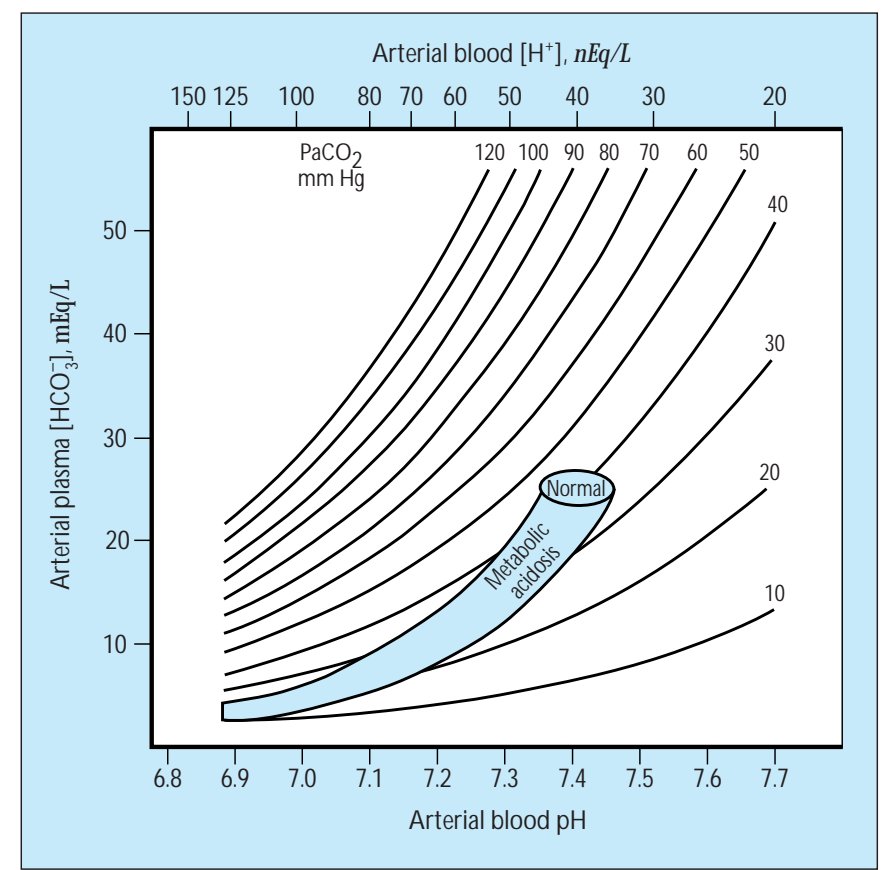

\section{FIGURE 6-15}

$\mathrm{N}$ inety-five percent confidence intervals for metabolic acidosis. $M$ etabolic acidosis is the acid-base disturbance initiated by a decrease in plasma bicarbonate concentration ([ $\left.\left.\mathrm{HCO}_{3}^{-}\right]\right)$. The resultant acidemia stimulates alveolar ventilation and leads to the secondary hypocapnia characteristic of the disorder. Extensive observations in humans encompassing a wide range of stable metabolic acidosis indicate a roughly linear relationship between the steadystate decrease in plasma bicarbonate concentration and the associated decrement in arterial carbon dioxide tension $\left(\mathrm{PaCO}_{2}\right)$. The slope of the steady state $\Delta \mathrm{PaCO}_{2}$ versus $\Delta\left[\mathrm{HCO}_{3}^{-}\right]$relationship has been estimated as approximately $1.2 \mathrm{~mm} \mathrm{H}$ g per $\mathrm{mEq} / \mathrm{L}$ decrease in plasma bicarbonate concentration. Such empiric observations have been used for construction of $95 \%$ confidence intervals for graded degrees of metabolic acidosis, represented by the area in color in the acid-base template. The black ellipse near the center of the figure indicates the normal range for the acid-base parameters [3]. Assuming a steady state is present, values falling within the area in color are consistent with but not diagnostic of simple metabolic acidosis. Acid-base values falling outside the area in color denote the presence of a mixed acid-base disturbance [4]. [H+]hydrogen ion concentration.

\section{SIGNS AND SYMPTOMS OF METABOLIC ACIDOSIS}

\begin{tabular}{|c|c|c|c|c|}
\hline $\begin{array}{l}\text { Respiratory } \\
\text { System }\end{array}$ & Cardiovascular System & Metabolism & $\begin{array}{l}\text { Central } \\
\text { Nervous System }\end{array}$ & Skeleton \\
\hline $\begin{array}{l}\text { Hyperventilation } \\
\text { Respiratory distress } \\
\text { and dyspnea } \\
\text { Decreased strength } \\
\text { of respiratory } \\
\text { muscles and } \\
\text { promotion of } \\
\text { muscle fatigue }\end{array}$ & $\begin{array}{l}\text { Impairment of cardiac } \\
\text { contractility, arteriolar } \\
\text { dilation, venoconstriction, } \\
\text { and centralization of } \\
\text { blood volume } \\
\text { Reductions in cardiac } \\
\text { output, arterial blood } \\
\text { pressure, and hepatic } \\
\text { and renal blood flow } \\
\text { Sensitization to reentrant } \\
\text { arrhythmias and reduction } \\
\text { in threshold for ventricular } \\
\text { fibrillation } \\
\text { Increased sympathetic } \\
\text { discharge but attenuation of } \\
\text { cardiovascular responsiveness } \\
\text { to catecholamines }\end{array}$ & $\begin{array}{l}\text { Increased } \\
\text { metabolic demands } \\
\text { Insulin resistance } \\
\text { Inhibition of } \\
\text { anaerobic glycolysis } \\
\text { Reduction in adenosine } \\
\text { triphosphate synthesis } \\
\text { Hyperkalemia } \\
\text { Increased } \\
\text { protein degradation }\end{array}$ & $\begin{array}{l}\text { Impaired metabolism } \\
\text { Inhibition of cell } \\
\text { volume regulation } \\
\text { Progressive obtundation } \\
\text { Coma }\end{array}$ & $\begin{array}{l}\text { Osteomalacia } \\
\text { Fractures }\end{array}$ \\
\hline
\end{tabular}

\section{FIGURE 6-16}

Signs and symptoms of metabolic acidosis. A mong the various clinical manifestations, particularly pernicious are the effects of severe acidemia (blood pH <7.20) on the cardiovascular system. Reductions in cardiac output, arterial blood pressure, and hepatic and renal blood flow can occur and lifethreatening arrhythmias can develop. Chronic acidemia, as it occurs in untreated renal tubular acidosis and uremic acidosis, can cause calcium dissolution from the bone mineral and consequent skeletal abnormalities. 


\begin{tabular}{|c|c|c|c|c|c|}
\hline \multirow{2}{*}{\multicolumn{2}{|c|}{ Normal }} & \multicolumn{4}{|c|}{ Metabolic acidosis } \\
\hline & & \multicolumn{2}{|c|}{$\begin{array}{l}\text { Normal anion gap } \\
\text { (hyperchloremic) }\end{array}$} & \multicolumn{2}{|c|}{$\begin{array}{l}\text { High anion gap } \\
\text { (normochloremic) }\end{array}$} \\
\hline \multirow{3}{*}{$\begin{array}{l}\mathrm{Na}^{+} \\
140\end{array}$} & \begin{tabular}{|c|}
$\mathrm{A}^{-10}$ \\
$\mathrm{HCO}_{3}^{-}$ \\
24 \\
\end{tabular} & & $\stackrel{\mathrm{A}^{-10}}{-} \mathrm{HCO}_{3}^{-} 4$ & & $A^{-} 30$ \\
\hline & $\begin{array}{l}\mathrm{Cl}^{-} \\
106\end{array}$ & $\begin{array}{l}\mathrm{Na}^{+} \\
140\end{array}$ & $\begin{array}{l}\mathrm{Cl}^{-} \\
126\end{array}$ & $\begin{array}{l}\mathrm{Na}^{+} \\
140\end{array}$ & $\begin{array}{l}\mathrm{Cl}^{-} \\
106\end{array}$ \\
\hline & & $\begin{array}{l}\text { Ca } \\
\text { Renal acidificati } \\
\text { Proximal rena } \\
\text { Classic distal t } \\
\text { Hyperkalemic } \\
\text { Early renal fail } \\
\text { Gastrointestina } \\
\text { Diarrhea } \\
\text { Small bowel Ic } \\
\text { Ureteral diver } \\
\text { Anion exchan } \\
\text { Ingestion of C } \\
\text { Acid infusion } \\
\mathrm{HCl} \\
\text { Arginine } \mathrm{HCl} \\
\text { Lysine } \mathrm{HCl}\end{array}$ & $\begin{array}{l}\text { Ises } \\
\text { on defects } \\
\text { tubular acidosis } \\
\text { ubular acidosis } \\
\text { distal tubular acidosis } \\
\text { ure } \\
\text { loss of bicarbonate } \\
\text { sses } \\
\text { sions } \\
\text { ge resins } \\
\mathrm{aCl}_{2}\end{array}$ & $\begin{array}{r}\text { Ca } \\
\text { Endogen } \\
\text { Ketoac } \\
\text { Diabe } \\
\text { S Alcoh } \\
\text { Starv } \\
\text { Uremia } \\
\text { Lactic } \\
\text { Exogeno } \\
\text { Osmol } \\
\text { M eth } \\
\text { Ethyle } \\
\text { Osmol } \\
\text { Salicy } \\
\text { Paralc }\end{array}$ & $\begin{array}{l}\text { luses } \\
\text { ous acid load } \\
\text { idosis } \\
\text { teses mellitus } \\
\text { oolism } \\
\text { ation } \\
\text { acidosis } \\
\text { us toxins } \\
\text { ar gap present } \\
\text { anol } \\
\text { ene glycol } \\
\text { ar gap absent } \\
\text { lates } \\
\text { dehyde }\end{array}$ \\
\hline
\end{tabular}

\section{FIGURE 6-17}

Causes of metabolic acidosis tabulated according to the prevailing pattern of plasma electrolyte composition. Assessment of the plasma unmeasured anion concentration (anion gap) is a very useful first step in approaching the differential diagnosis of unexplained metabolic acidosis. The plasma anion gap is calculated as the difference between the sodium concentration and the sum of chloride and bicarbonate concentrations. Under normal circumstances, the plasma anion gap is primarily composed of the net negative charges of plasma proteins, predominantly albumin, with a smaller contribution from many other organic and inorganic anions. The normal value of the plasma anion gap is $12 \pm 4$ (mean \pm 2 SD) $\mathrm{mEq} / \mathrm{L}$, where SD is the standard deviation. However, recent introduction of ion-specific electrodes has shifted the normal anion gap to the range of about $6 \pm 3 \mathrm{mEq} / \mathrm{L}$. In one pattern of metabolic acidosis, the decrease in bicarbonate concentration is offset by an increase in the concentration of chloride, with the plasma anion gap remaining normal. In the other pattern, the decrease in bicarbonate is balanced by an increase in the concentration of unmeasured anions (ie, anions not measured routinely), with the plasma chloride concentration remaining normal.

\section{Lactic acidosis}

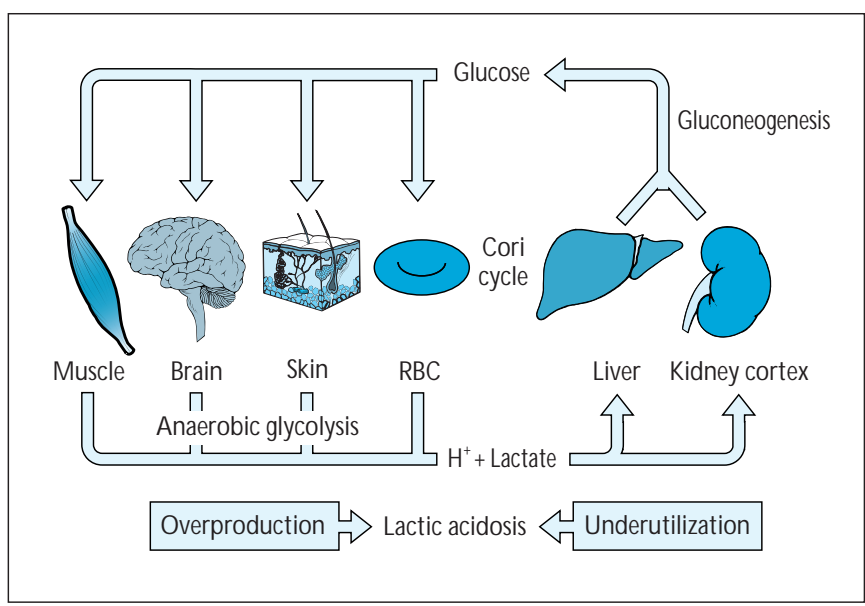

\section{FIGURE 6-18}

L actate-producing and lactate-consuming tissues under basal conditions and pathogenesis of lactic acidosis. Although all tissues pro- duce lactate during the course of glycolysis, those listed contribute substantial quantities of lactate to the extracellular fluid under normal aerobic conditions. In turn, lactate is extracted by the liver and to a lesser degree by the renal cortex and primarily is reconverted to glucose by way of gluconeogenesis (a smaller portion of lactate is oxidized to carbon dioxide and water). This cyclical relationship between glucose and lactate is known as the Cori cycle. The basal turnover rate of lactate in humans is enormous, on the order of 15 to $25 \mathrm{mEq} / \mathrm{kg} / \mathrm{d}$. Precise equivalence between lactate production and its use ensures the stability of plasma lactate concentration, normally ranging from 1 to $2 \mathrm{mEq} / \mathrm{L}$. H ydrogen ions $\left(\mathrm{H}^{+}\right)$released during lactate generation are quantitatively consumed during the use of lactate such that acid-base balance remains undisturbed. Accumulation of lactate in the circulation, and consequent lactic acidosis, is generated whenever the rate of production of lactate is higher than the rate of utilization. The pathogenesis of this imbalance reflects overproduction of lactate, underutilization, or both. $\mathrm{M}$ ost cases of persistent lactic acidosis actually involve both overproduction and underutilization of lactate. During hypoxia, almost all tissues can release lactate into the circulation; indeed, even the liver can be converted from the premier consumer of lactate to a net producer $[1,14]$. 


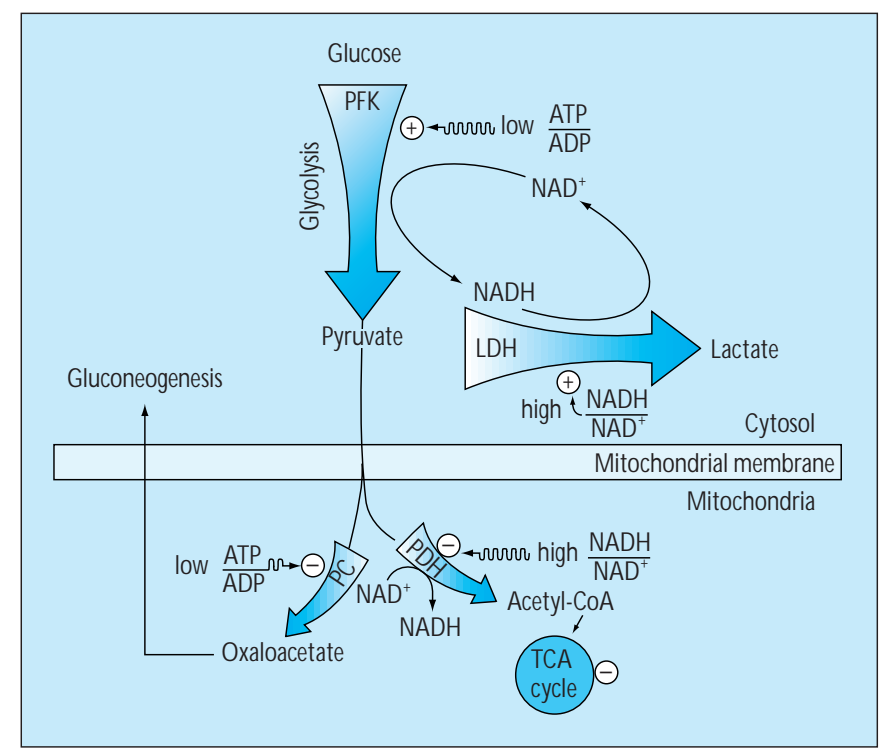

FIGURE 6-19

H ypoxia-induced lactic acidosis. Accumulation of lactate during hypoxia, by far the most common clinical setting of the disorder, originates from impaired mitochondrial oxidative function that reduces the availability of adenosine triphosphate (ATP) and NAD+ (oxidized nicotinamide adenine dinucleotide) within the cytosol. In turn, these changes cause cytosolic accumulation of pyruvate as a consequence of both increased production and decreased utilization. Increased production of pyruvate occurs because the reduced cytosolic supply of ATP stimulates the activity of 6-phosphofructokinase (PFK), thereby accelerating glycolysis. D ecreased utilization of pyruvate reflects the fact that both pathways of its consumption depend on mitochondrial oxidative reactions: oxidative decarboxylation to acetyl coenzyme A (acetyl-C OA), a reaction catalyzed by pyruvate dehydrogenase (PDH), requires a continuous supply of NAD+; and carboxylation of pyruvate to oxaloacetate, a reaction catalyzed by pyruvate carboxylase (PC), requires ATP. The increased $[\mathrm{NADH}] /[\mathrm{NAD+}$ ] ratio (NADH refers to the reduced form of the dinucleotide) shifts the equilibrium of the lactate dehydrogenase $(\mathrm{LDH})$ reaction (that catalyzes the interconversion of pyruvate and lactate) to the right. In turn, this change coupled with the accumulation of pyruvate in the cytosol results in increased accumulation of lactate. Despite the prevailing mitochondrial dysfunction, continuation of glycolysis is assured by the cytosolic regeneration of $\mathrm{NAD}+$ during the conversion of pyruvate to lactate. Provision of NAD + is required for the oxidation of glyceraldehyde 3-phosphate, a key step in glycolysis. Thus, lactate accumulation can be viewed as the toll paid by the organism to maintain energy production during anaerobiosis (hypoxia) [14]. ADP-adenosine diphosphate; TCA cycle-tricarboxylic acid cycle.

\section{CAUSES OF LACTIC ACIDOSIS}

\section{Type A:}

Impaired Tissue 0xygenation

Shock

Severe hypoxemia

Generalized convulsions

Vigorous exercise

Exertional heat stroke

Hypothermic shivering

Massive pulmonary emboli

Severe heart failure

Profound anemia

Mesenteric ischemia

Carbon monoxide poisoning

Cyanide poisoning

\section{Type B: Preserved Tissue Oxygenation}

\begin{tabular}{ll}
\hline Diseases and conditions & Drugs and toxins \\
Diabetes mellitus & Epinephrine, \\
Hypoglycemia & norepinephrine, \\
Renal failure & vasoconstrictor agents \\
Hepatic failure & Salicylates \\
Severe infections & Ethanol \\
Alkaloses & Methanol \\
Malignancies (lymphoma, & Ethylene glycol \\
leukemia, sarcoma) & Biguanides \\
Thiamine deficiency & Acetaminophen \\
Acquired & Zidovudine \\
immunodeficiency syndrome & Fructose, sorbitol, \\
Pheochromocytoma & and xylitol \\
Iron deficiency & Streptozotocin \\
D-Lactic acidosis & Isoniazid \\
Congenital enzymatic defects & Nitroprusside \\
& Papaverine \\
& Nalidixic acid
\end{tabular}

\section{FIGURE 6-20}

Conventionally, two broad types of lactic acidosis are recognized. In type A, clinical evidence exists of impaired tissue oxygenation. In type $B$, no such evidence is apparent. O ccasionally, the distinction between the two types may be less than obvious. Thus, inadequate tissue oxygenation can at times defy clinical detection, and tissue hypoxia can be a part of the pathogenesis of certain causes of type $B$ lactic acidosis. M ost cases of lactic acidosis are caused by tissue hypoxia arising from circulatory failure $[14,15]$. 


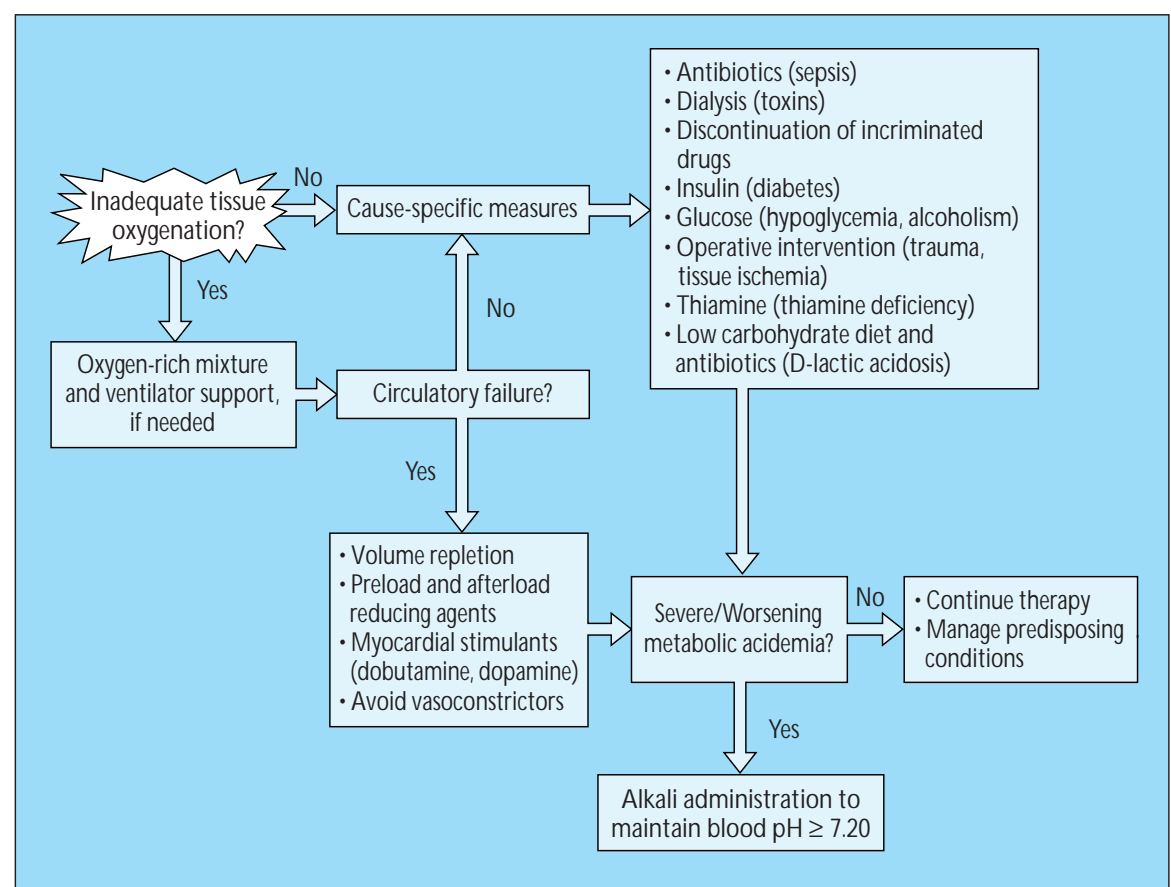

\section{Diabetic ketoacidosis and nonketotic hyperglycemia}

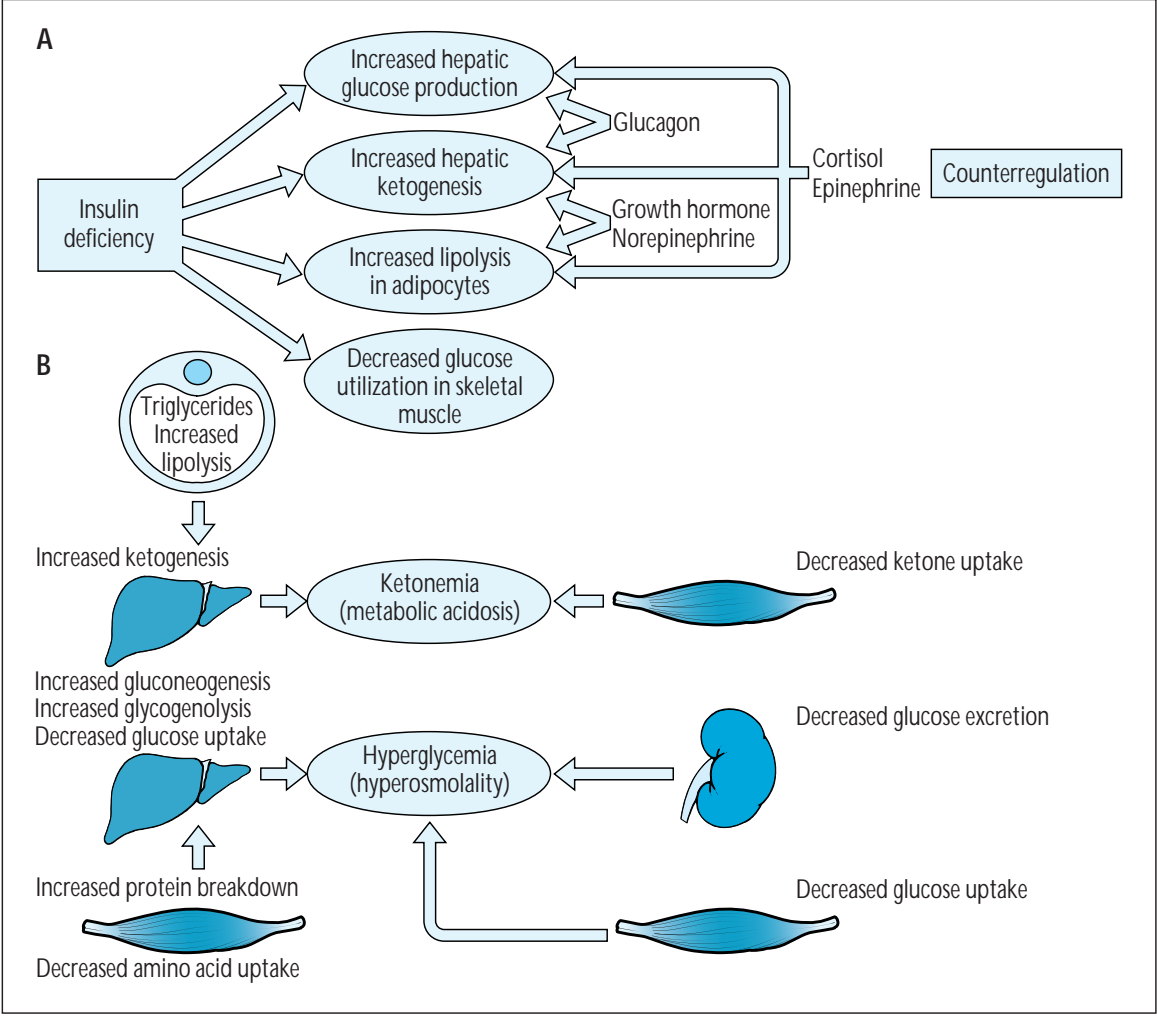

\section{FIGURE 6-21}

Lactic acidosis management. $M$ anagement of lactic acidosis should focus primarily on securing adequate tissue oxygenation and on aggressively identifying and treating the underlying cause or predisposing condition. M onitoring of the patient's hemodynamics, oxygenation, and acid-base status should be used to guide therapy. In the presence of severe or worsening metabolic acidemia, these measures should be supplemented by judicious administration of sodium bicarbonate, given as an infusion rather than a bolus. Alkali administration should be regarded as a temporizing maneuver adjunctive to cause-specific measures. Given the ominous prognosis of lactic acidosis, clinicians should strive to prevent its development by maintaining adequate fluid balance, optimizing cardiorespiratory function, managing infection, and using drugs that predispose to the disorder cautiously. Preventing the development of lactic acidosis is all the more important in patients at special risk for developing it, such as those with diabetes mellitus or advanced cardiac, respiratory, renal, or hepatic disease [1,14-16].

\section{FIGURE 6-22}

Role of insulin deficiency and the counterregulatory hormones, and their respective sites of action, in the pathogenesis of hyperglycemia and ketosis in diabetic ketoacidosis (DKA).A, M etabolic processes affected by insulin deficiency, on the one hand, and excess of glucagon, cortisol, epinephrine, norepinephrine, and grow th hormone, on the other. B, The roles of the adipose tissue, liver, skeletal muscle, and kidney in the pathogenesis of hyperglycemia and ketonemia. Impairment of glucose oxidation in most tissues and excessive hepatic production of glucose are the main determinants of hyperglycemia. Excessive counterregulation and the prevailing hypertonicity, metabolic acidosis, and electrolyte imbalance superimpose a state of insulin resistance. Prerenal azotemia caused by volume depletion can contribute significantly to severe hyperglycemia. Increased hepatic production of ketones and their reduced utilization by peripheral tissues account for the ketonemia typically observed in DKA. 


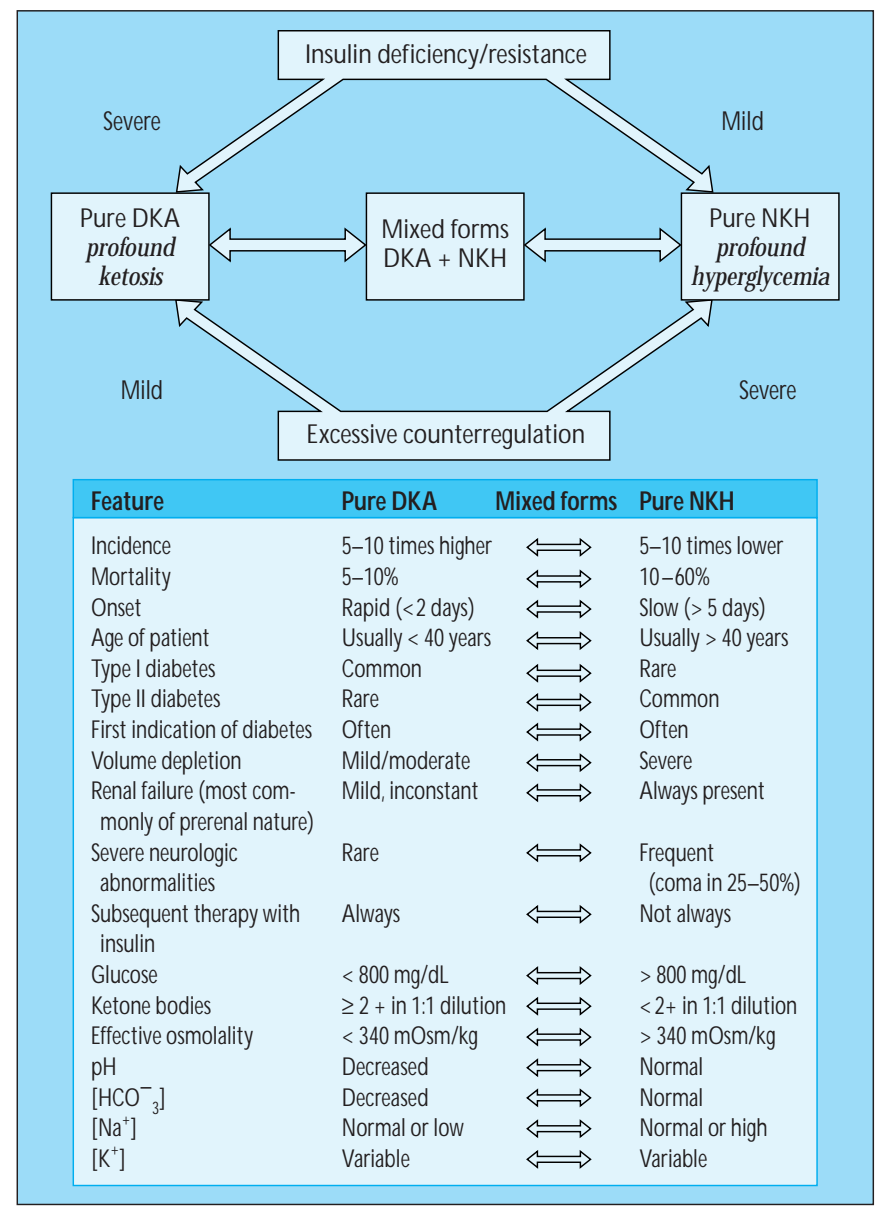

\section{FIGURE 6-23}

Clinical features of diabetic ketoacidosis (DKA) and nonketotic hyperglycemia (N KH). DKA and NKH are the most important acute metabolic complications of patients with uncontrolled diabetes mellitus. These disorders share the same overall pathogenesis that includes insulin deficiency and resistance and excessive counterregulation; however, the importance of each of these endocrine abnormalities differs significantly in DKA and $\mathrm{NKH}$. As depicted here, pure N KH is characterized by profound hyperglycemia, the result of mild insulin deficiency and severe counterregulation (eg, high glucagon levels). In contrast, pure DKA is characterized by profound ketosis that largely is due to severe insulin deficiency, with counterregulation being generally of lesser importance. These pure forms define a continuum that includes mixed forms incorporating clinical and biochemical features of both DKA and NKH. Dyspnea and Kussmaul's respiration result from the metabolic acidosis of DKA, which is generally absent in NKH. Sodium and water deficits and secondary renal dysfunction are more severe in NKH than in DKA. These deficits also play a pathogenetic role in the profound hypertonicity characteristic of N KH. The severe hyperglycemia of N KH, often coupled with hypernatremia, increases serum osmolality, thereby causing the characteristic functional abnormalities of the central nervous system. Depression of the sensorium, somnolence, obtundation, and coma, are prominent manifestations of $\mathrm{NKH}$. The degree of obtundation correlates with the severity of serum hypertonicity [17].

\section{MANAGEMENT OF DIABETIC KETOACIDOSISAND NONKETOTIC HYPERGLYCEMIA}

\begin{tabular}{|c|c|c|c|}
\hline Insulin & Fluid Administration & Potassium repletion & Alkali \\
\hline $\begin{array}{l}\text { 1. Give initial IV bolus of } 0.2 \mathrm{U} / \mathrm{kg} \text { actual body weight. } \\
\text { 2. Add } 100 \mathrm{U} \text { of regular insulin to } 1 \mathrm{~L} \text { of normal saline ( } 0.1 \\
\mathrm{U} / \mathrm{mL} \text { ), and follow with continuous IV drip of } 0.1 \mathrm{U} / \mathrm{kg} \\
\text { actual body weight per } \mathrm{h} \text { until correction of ketosis. } \\
\text { 3. Give double rate of infusion if the blood glucose level } \\
\text { does not decrease in a } 2 \text {-h interval (expected decrease } \\
\text { is } 40-80 \mathrm{mg} / \mathrm{dL} / \mathrm{h} \text { or } 10 \% \text { of the initial value.) } \\
\text { 4. Give } \mathrm{SQ} \text { dose (10- } 30 \mathrm{U} \text { ) of regular insulin when ketosis } \\
\text { is corrected and the blood glucose level decreases to } \\
300 \mathrm{mg} / \mathrm{dL} \text {, and continue with } \mathrm{SQ} \text { insulin injection } \\
\text { every } 4 \mathrm{~h} \text { on a sliding scale (ie, } 5 \mathrm{U} \text { if below } 150,10 \mathrm{U} \text { if } \\
150-200,15 \mathrm{U} \text { if } 200-250 \text {, and } 20 \mathrm{U} \text { if } 250-300 \mathrm{mg} / \mathrm{dL} \text { ). }\end{array}$ & $\begin{array}{l}\text { Shock absent: Normal saline ( } 0.9 \% \mathrm{NaCl}) \\
\text { at } 7 \mathrm{~mL} / \mathrm{kg} / \mathrm{h} \text { for } 4 \mathrm{~h} \text {, and half this } \\
\text { rate thereafter } \\
\text { Shock present: Normal saline and plasma } \\
\text { expanders (ie,albumin, low molecular } \\
\text { weight dextran) at maximal possible rate } \\
\text { Start a glucose-containing solution } \\
\text { (eg, } 5 \% \text { dextrose in water) when blood } \\
\text { glucose level decreases to } 250 \mathrm{mg} / \mathrm{dL} \text {. }\end{array}$ & $\begin{array}{l}\text { Potassium chloride should be } \\
\text { added to the third liter of IV } \\
\text { infusion and subsequently } \\
\text { if urinary output is at least } \\
30-60 \mathrm{~mL} / \mathrm{h} \text { and plasma [K+] } \\
<5 \mathrm{mEq} / \mathrm{L} \text {. } \\
\text { Add } \mathrm{K}^{+} \text {to the initial } 2 \mathrm{~L} \text { of IV } \\
\text { fluids if initial plasma [K+] } \\
<4 \mathrm{mEq} / \mathrm{L} \text { and adequate } \\
\text { diuresis is secured. }\end{array}$ & $\begin{array}{l}\text { Half-normal saline }(0.45 \% \mathrm{NaCl}) \text { plus } \\
1-2 \text { ampules }(44-88 \mathrm{mEq}) \mathrm{NaHCO}_{3} \\
\text { per liter when blood pH }<7.0 \text { or } \\
\text { total } \mathrm{CO}_{2}<5 \mathrm{mmol} / \mathrm{L} \text {; in hyper- } \\
\text { chloremic acidosis, add } \mathrm{NaHCO}_{3} \\
\text { when pH }<7.20 \text {; discontinue } \\
\mathrm{NaHCO}_{3} \text { in IV infusion when total } \\
\mathrm{CO}_{2}>8-10 \mathrm{mmol} / \mathrm{L} \text {. }\end{array}$ \\
\hline
\end{tabular}

$\mathrm{CO}_{2}$ - carbon dioxide; IV-intravenous; $\mathrm{K}^{+}$- potassium ion; $\mathrm{NaCl}$ - sodium chloride; $\mathrm{NaHCO}_{3}$ - sodium bicarbonate; $\mathrm{SQ}$ - subcutaneous.

\section{FIGURE 6-24}

Diabetic ketoacidosis (DKA) and nonketotic hyperglycemia (N KH) management. Administration of insulin is the cornerstone of management for both DKA and N KH. Replacement of the prevailing water, sodium, and potassium deficits is also required. Alkali are administered only under certain circumstances in DKA and virtually never in
$\mathrm{NKH}$, in which ketoacidosis is generally absent. Because the fluid deficit is generally severe in patients with $\mathrm{NKH}$, many of whom have preexisting heart disease and are relatively old, safe fluid replacement may require monitoring of central venous pressure, pulmonary capillary wedge pressure, or both $[1,17,18]$. 


\section{Renal tubular acidosis}

\section{FEATURES OF THE RENAL TUBULAR ACIDOSIS (RTA) SYNDROMES}

\begin{tabular}{|c|c|c|c|}
\hline Feature & Proximal RTA & Classic Distal RTA & Hyperkalemic Distal RTA \\
\hline $\begin{array}{l}\text { Plasma bicarbonate } \\
\text { ion concentration }\end{array}$ & $14-18 \mathrm{mEq} / \mathrm{L}$ & $\begin{array}{l}\text { Variable, may be } \\
<10 \mathrm{mEq} / \mathrm{L}\end{array}$ & $15-20 \mathrm{mEq} / \mathrm{L}$ \\
\hline $\begin{array}{l}\text { Plasma chloride } \\
\text { ion concentration }\end{array}$ & Increased & Increased & Increased \\
\hline $\begin{array}{l}\text { Plasma potassium } \\
\text { ion concentration }\end{array}$ & Mildly decreased & $\begin{array}{l}\text { Mildly to } \\
\text { severely decreased }\end{array}$ & Mildly to severely increased \\
\hline Plasma anion gap & Normal & Normal & Normal \\
\hline Glomerular filtration rate & $\begin{array}{l}\text { Normal or } \\
\text { slightly decreased }\end{array}$ & $\begin{array}{l}\text { Normal or } \\
\text { slightly decreased }\end{array}$ & $\begin{array}{l}\text { Normal to } \\
\text { moderately decreased }\end{array}$ \\
\hline Urine pH during acidosis & $\leq 5.5$ & $>6.0$ & $\leq 5.5$ \\
\hline Urine pH after acid loading & $\leq 5.5$ & $>6.0$ & $\leq 5.5$ \\
\hline U-B $\mathrm{PCO}_{2}$ in alkaline urine & Normal & Decreased & Decreased \\
\hline $\begin{array}{l}\text { Fractional excretion of } \\
\mathrm{HCO}_{3}^{-} \text {at normal }\left[\mathrm{HCO}_{3}^{-}\right]_{\mathrm{p}}\end{array}$ & $>15 \%$ & $<5 \%$ & $<5 \%$ \\
\hline $\mathrm{Tm} \mathrm{HCO}_{3}^{-}$ & Decreased & Normal & Normal \\
\hline Nephrolithiasis & Absent & Present & Absent \\
\hline Nephrocalcinosis & Absent & Present & Absent \\
\hline Osteomalacia & Present & Present & Absent \\
\hline Fanconi's syndrome* & Usually present & Absent & Absent \\
\hline Alkali therapy & High dose & Low dose & Low dose \\
\hline
\end{tabular}

$\mathrm{Tm} \mathrm{HCO}_{3}^{-}$- maximum reabsorption of bicarbonate; $\mathrm{U}-\mathrm{B} \mathrm{PCO}_{2}$ - difference between partial pressure of carbon dioxide values in urine and arterial blood.

*This syndrome signifies generalized proximal tubule dysfunction and is characterized by impaired reabsorption of glucose, amino acids, phosphate, and urate.

\section{FIGURE 6-25}

Renal tubular acidosis (RTA) defines a group of disorders in which tubular hydrogen ion secretion is impaired out of proportion to any reduction in the glomerular filtration rate. These disorders are characterized by normal anion gap (hyperchloremic) metabolic acidosis. The defects responsible for impaired acidification give rise to three distinct syndromes known as proximal RTA (type 2), classic distal RTA (type 1), and hyperkalemic distal RTA (type 4). 


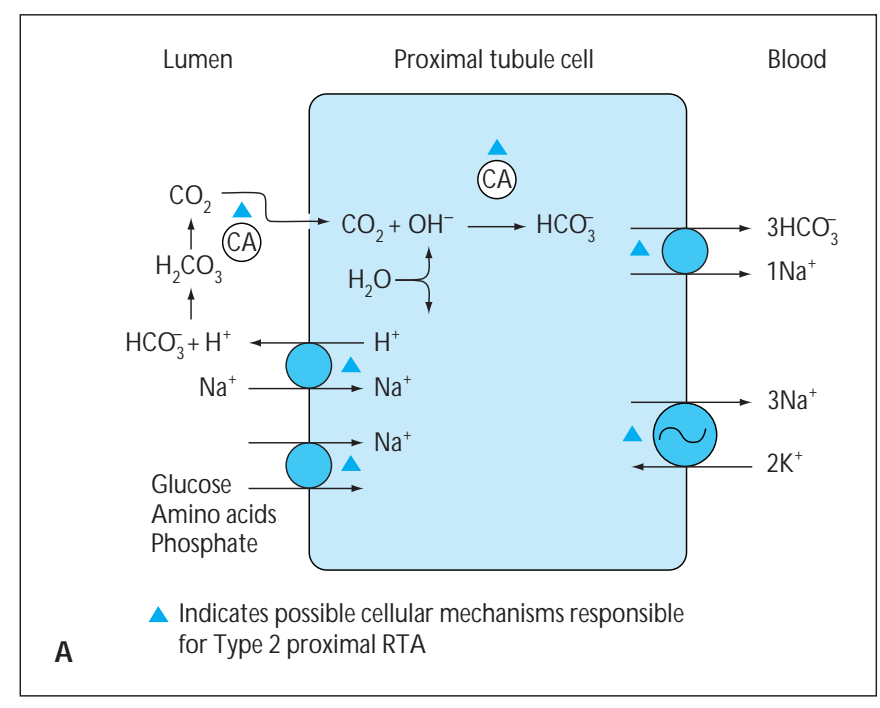

\section{FIGURE 6-26}

A and B, Potential defects and causes of proximal renal tubular acidosis (RTA) (type 2). Excluding the case of carbonic anhydrase inhibitors, the nature of the acidification defect responsible for bicarbonate $\left(\mathrm{HCO}_{3}\right)$ wastage remains unknown. It might represent defects in the luminal sodium ion- hydrogen ion $\left(\mathrm{Na}^{+}-\mathrm{H}^{+}\right)$ exchanger, basolateral $\mathrm{Na}^{+}-3 \mathrm{HCO}_{3}^{-}$cotransporter, or carbonic anhydrase activity. M ost patients with proximal RTA have additional defects in proximal tubule function (Fanconi's syndrome); this generalized proximal tubule dysfunction might reflect a defect in the basolateral $\mathrm{N} \mathrm{a}^{+}-\mathrm{K}+$ adenosine triphosphatase. $\mathrm{K}+$ - potassium ion; CA - carbonic anhydrase. Causes of proximal renal tubular acidosis (RTA) (type 2). An idiopathic form and cystinosis are the most common causes of proximal RTA in children. In adults, multiple myeloma and carbonic anhydrase inhibitors (eg, acetazolamide) are the major causes. Ifosfamide is an increasingly common cause of the disorder in both age groups.

\section{B. CAUSES OF PROXIMAL RENAL TUBULAR ACIDOSIS}

Selective defect (isolated bicarbonate wasting)

Primary (no obvious associated disease)

Genetically transmitted

Transient (infants)

Due to altered carbonic anhydrase activity

Acetazolamide

Sulfanilamide

M afenide acetate

Genetically transmitted

Idiopathic

Osteopetrosis with carbonic

anhydrase Il deficiency

York-Yendt syndrome

Generalized defect (associated with multiple dysfunctions of the proximal tubule)

Primary (no obvious associated disease)

Sporadic

Genetically transmitted

Genetically transmitted systemic disease

Tyrosinemia

Wilson's disease

Lowe syndrome

Hereditary fructose intolerance (during

administration of fructose)

Cystinosis

Pyruvate carboxylate deficiency

Metachromatic leukodystrophy

Methylmalonic acidemia

Conditions associated with chronic hypocalcemia and secondary hyperparathyroidism

Vitamin $D$ deficiency or resistance

Vitamin $D$ dependence
Dysproteinemic states Multiple myeloma M onoclonal gammopathy

Drug- or toxin-induced Outdated tetracycline 3-M ethylchromone Streptozotocin Lead Mercury Arginine Valproic acid Gentamicin Ifosfamide

Tubulointerstitial diseases Renal transplantation Sjögren's syndrome Medullary cystic disease

Other renal diseases Nephrotic syndrome Amyloidosis

Miscellaneous Paroxysmal nocturnal hemoglobinuria Hyperparathyroidism 


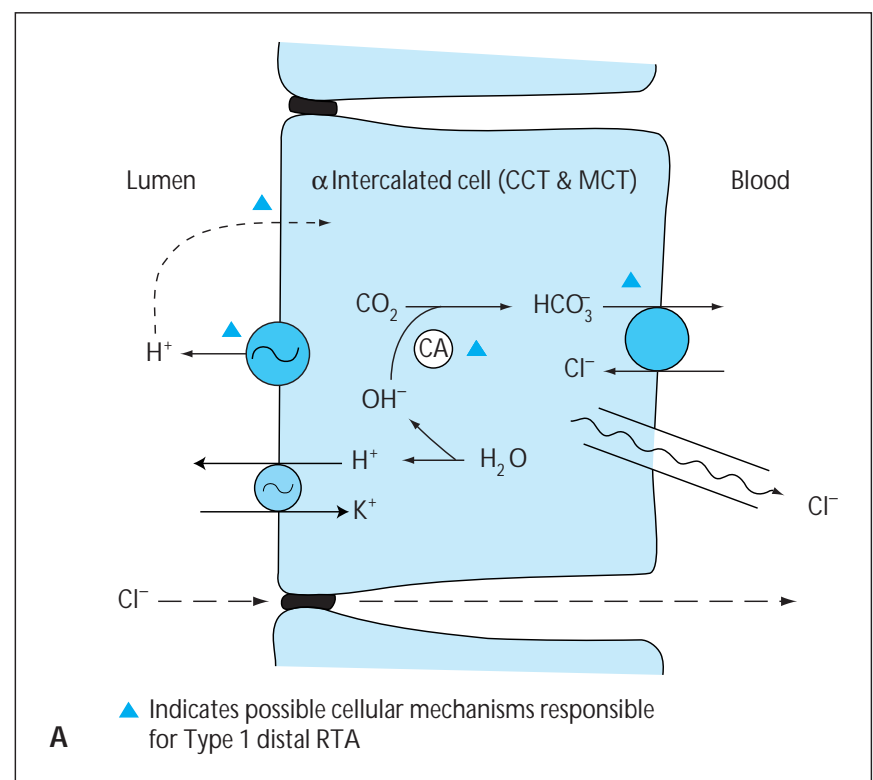

\section{FIGURE 6-27}

A and B, Potential defects and causes of classic distal renal tubular acidosis (RTA) (type 1). Potential cellular defects underlying classic distal RTA include a faulty luminal hydrogen ion-adenosine triphosphatase $(H+$ pump failure or secretory defect), an abnormality in the basolateral bicarbonate ion-chloride ion exchanger, inadequacy of carbonic anhydrase activity, or an increase in the luminal membrane permeability for hydrogen ions (backleak of protons or permeability defect). M ost of the causes of classic distal RTA likely reflect a secretory defect, whereas amphotericin B is the only established cause of a permeability defect. The hereditary form is the most common cause of this disorder in children. M ajor causes in adults include autoimmune disorders (eg, Sjögren's syndrome) and hypercalciuria [19]. CA-carbonic anhydrase.

\section{B. CAUSES OF CLASSIC DISTAL RENAL TUBULAR ACIDOSIS}

Primary (no obvious associated disease)

Sporadic

Genetically transmitted

Autoimmune disorders

Hypergammaglobulinemia

Hyperglobulinemic purpura

Cryoglobulinemia

Familial

Sjögren's syndrome

Thyroiditis

Pulmonary fibrosis

Chronic active hepatitis

Primary biliary cirrhosis

Systemic lupus erythematosus

Vasculitis

Genetically transmitted systemic disease

Ehlers-Danlos syndrome

Hereditary elliptocytosis

Sickle cell anemia

Marfan syndrome

Carbonic anhydrase I deficiency

or alteration

Osteopetrosis with carbonic

anhydrase II deficiency

Medullary cystic disease

Neuroaxonal dystrophy
Disorders associated with nephrocalcinosis

Primary or familial hyperparathyroidism Vitamin D intoxication

Milk-alkali syndrome

Hyperthyroidism

Idiopathic hypercalciuria

Genetically transmitted

Sporadic

Hereditary fructose intolerance

(after chronic fructose ingestion)

Medullary sponge kidney

Fabry's disease

Wilson's disease

Drug- or toxin-induced

Amphotericin B

Toluene

Analgesics

Lithium

Cyclamate

Balkan nephropathy

Tubulointerstitial diseases

Chronic pyelonephritis

Obstructive uropathy

Renal transplantation

Leprosy

Hyperoxaluria 


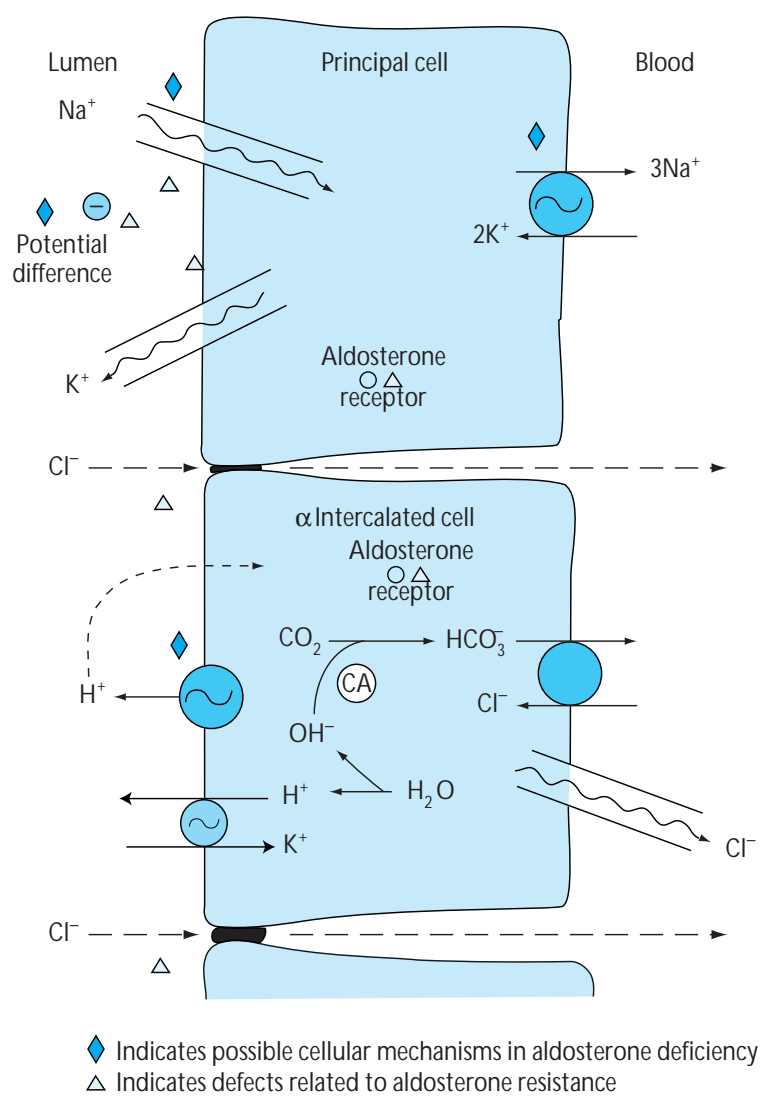

A

\section{FIGURE 6-28}

A and B, Potential defects and causes of hyperkalemic distal renal tubular acidosis (RTA) (type 4). This syndrome represents the most common type of RTA encountered in adults. The characteristic hyperchloremic metabolic acidosis in the company of hyperkalemia emerges as a consequence of generalized dysfunction of the collecting tubule, including diminished sodium reabsorption and impaired hydrogen ion and potassium secretion. The resultant hyperkalemia causes impaired ammonium excretion that is an important contribution to the generation of the metabolic acidosis. The causes of this syndrome are broadly classified into disorders resulting in aldosterone deficiency and those that impose resistance to the action of aldosterone. Aldosterone deficiency can arise from

\section{B. CAUSES OF HYPERKALEMIC DISTAL RENAL TUBULAR ACIDOSIS}

$\begin{array}{cc}\text { Deficiency of aldosterone } & \text { Resistance to aldosterone action } \\ \text { Associated with glucocorticoid deficiency } & \text { Pseudohypoaldosteronism type I } \\ \text { Addison's disease } & \text { (with salt wasting) } \\ \text { Bilateral adrenalectomy } & \text { Childhood forms with } \\ \text { Enzymatic defects } & \text { obstructive uropathy } \\ \text { 21-Hydroxylase deficiency } & \text { Adult forms with } \\ \text { 3- } \beta \text {-ol-Dehydrogenase deficiency } & \text { renal insufficiency } \\ \text { Desmolase deficiency } & \text { Spironolactone } \\ \text { Acquired immunodeficiency syndrome } & \text { Pseudohypoaldosteronism type II } \\ \text { Isolated aldosterone deficiency } & \text { (without salt wasting) } \\ \text { Genetically transmitted } & \text { Combined aldosterone deficiency } \\ \text { Corticosterone methyl } & \text { and resistance } \\ \text { oxidase deficiency } & \text { Deficient renin secretion } \\ \text { Transient (infants) } & \text { Cyclosporine nephrotoxicity } \\ \text { Sporadic } & \text { Uncertain renin status } \\ \text { Heparin } & \text { Voltage-mediated defects } \\ \text { Deficient renin secretion } & \text { Obstructive uropathy } \\ \text { Diabetic nephropathy } & \text { Sickle cell anemia } \\ \text { Tubulointerstitial renal disease } & \text { Lithium } \\ \text { Nonsteroidal antiinflammatory drugs } & \text { Triamterene } \\ \beta \text {-adrenergic blockers } & \text { Amiloride } \\ \text { Acquired immunodeficiency syndrome } & \text { Trimethoprim, pentamidine } \\ \text { Renal transplantation } & \text { Renal transplantation } \\ \text { Angiotensin l-converting enzyme inhibition } & \\ \text { Endogenous } & \\ \text { Captopril and related drugs } & \\ \text { Angiotensin AT, receptor blockers } & \end{array}$

hyporeninemia, impaired conversion of angiotensin I to angiotensin II, or abnormal aldosterone synthesis. Aldosterone resistance can reflect the following: blockade of the mineralocorticoid receptor; destruction of the target cells in the collecting tubule (tubulointerstitial nephropathies); interference with the sodium channel of the principal cell, thereby decreasing the lumen-negative potential difference and thus the secretion of potassium and hydrogen ions (voltage-mediated defect); inhibition of the basolateral sodium ion, potassium ion-adenosine triphosphatase; and enhanced chloride ion permeability in the collecting tubule, with consequent shunting of the transepithelial potential difference. Some disorders cause combined aldosterone deficiency and resistance [20]. 


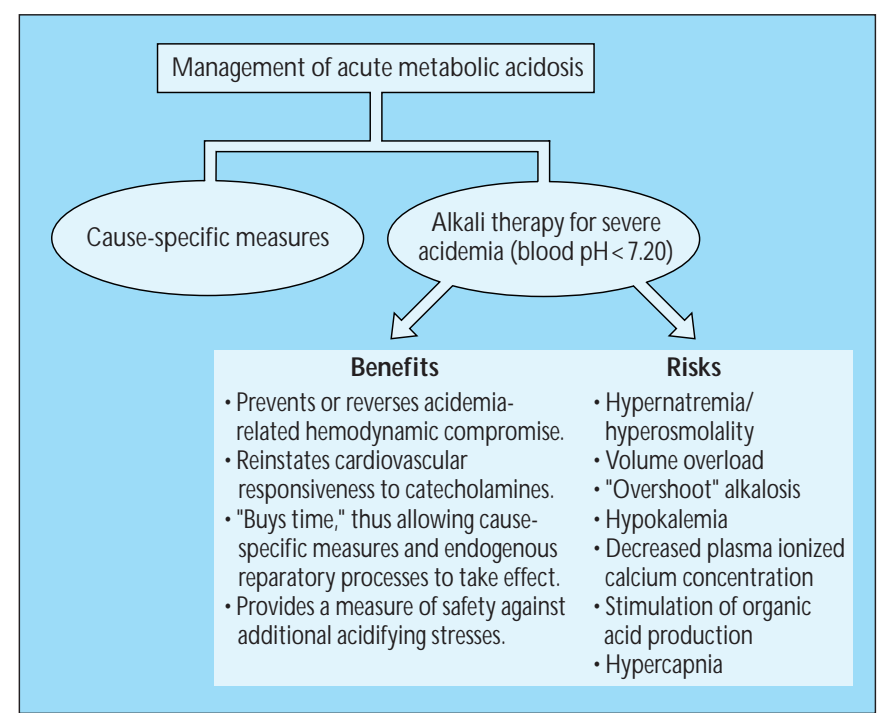

\section{FIGURE 6-29}

Treatment of acute metabolic acidosis. Whenever possible, causespecific measures should be at the center of treatment of metabolic acidosis. In the presence of severe acidemia, such measures should be supplemented by judicious administration of sodium bicarbonate. The goal of alkali therapy is to return the blood pH to a safer level of about 7.20. Anticipated benefits and potential risks of alkali therapy are depicted here [1].

\section{Metabolic Alkalosis}

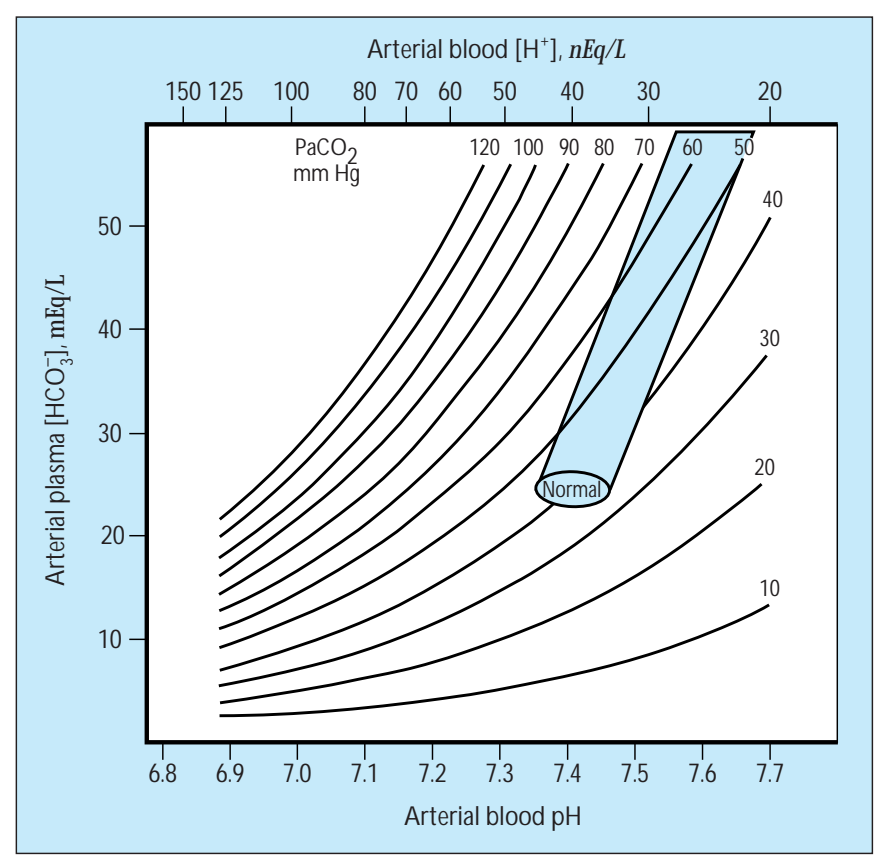

\section{FIGURE 6-30}

$\mathrm{N}$ inety-five percent confidence intervals for metabolic alkalosis. $M$ etabolic alkalosis is the acid-base disturbance initiated by an increase in plasma bicarbonate concentration ([ $\left.\left.\mathrm{HCO}_{3}^{-}\right]\right)$. The resultant alkalemia dampens alveolar ventilation and leads to the secondary hypercapnia characteristic of the disorder. Available observations in humans suggest a roughly linear relationship between the steady-state increase in bicarbonate concentration and the associated increment in the arterial carbon dioxide tension $\left(\mathrm{PaCO}_{2}\right)$. Although data are limited, the slope of the steadystate $\triangle \mathrm{PaCO}_{2}$ versus $\Delta\left[\mathrm{HCO}_{3}^{-}\right]$relationship has been estimated as about a $0.7 \mathrm{~mm} \mathrm{Hg}$ per $\mathrm{mEq} / \mathrm{L}$ increase in plasma bicarbonate concentration. The value of this slope is virtually identical to that in dogs that has been derived from rigorously controlled observations [21]. Empiric observations in humans have been used for construction of $95 \%$ confidence intervals for graded degrees of metabolic alkalosis represented by the area in color in the acid-base template. The black ellipse near the center of the figure indicates the normal range for the acid-base parameters [3]. Assuming a steady state is present, values falling within the area in color are consistent with but not diagnostic of simple metabolic alkalosis. A cid-base values falling outside the area in color denote the presence of a mixed acid-base disturbance [4]. $\left[\mathrm{H}^{+}\right]$- hydrogen ion concentration. 


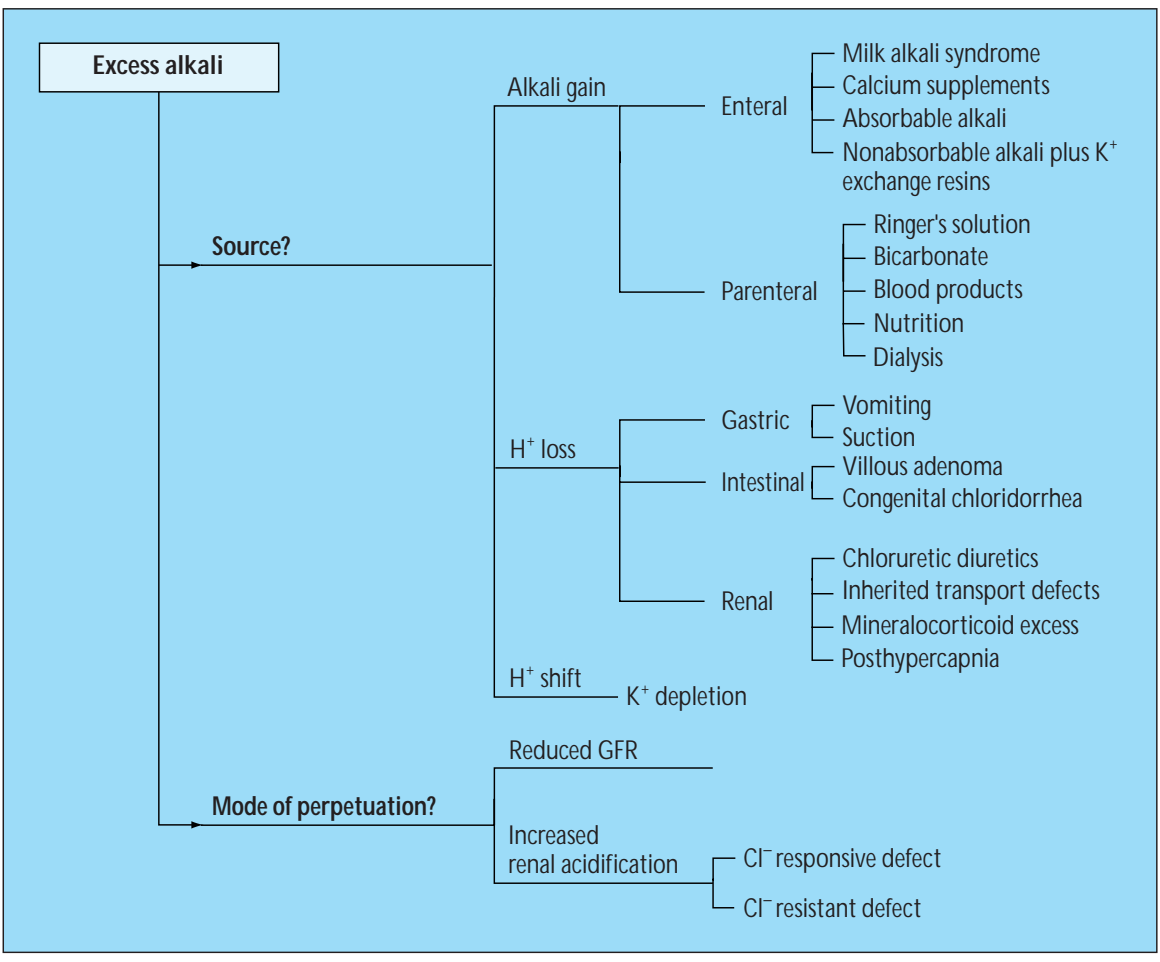

\section{FIGURE 6-31}

Pathogenesis of metabolic alkalosis. Two crucial questions must be answered when evaluating the pathogenesis of a case of metabolic alkalosis. 1) What is the source of the excess alkali? Answering this question addresses the primary event responsible for generating the hyperbicarbonatemia. 2) What factors perpetuate the hyperbicarbonatemia? Answering this question addresses the pathophysiologic events that maintain the metabolic alkalosis.

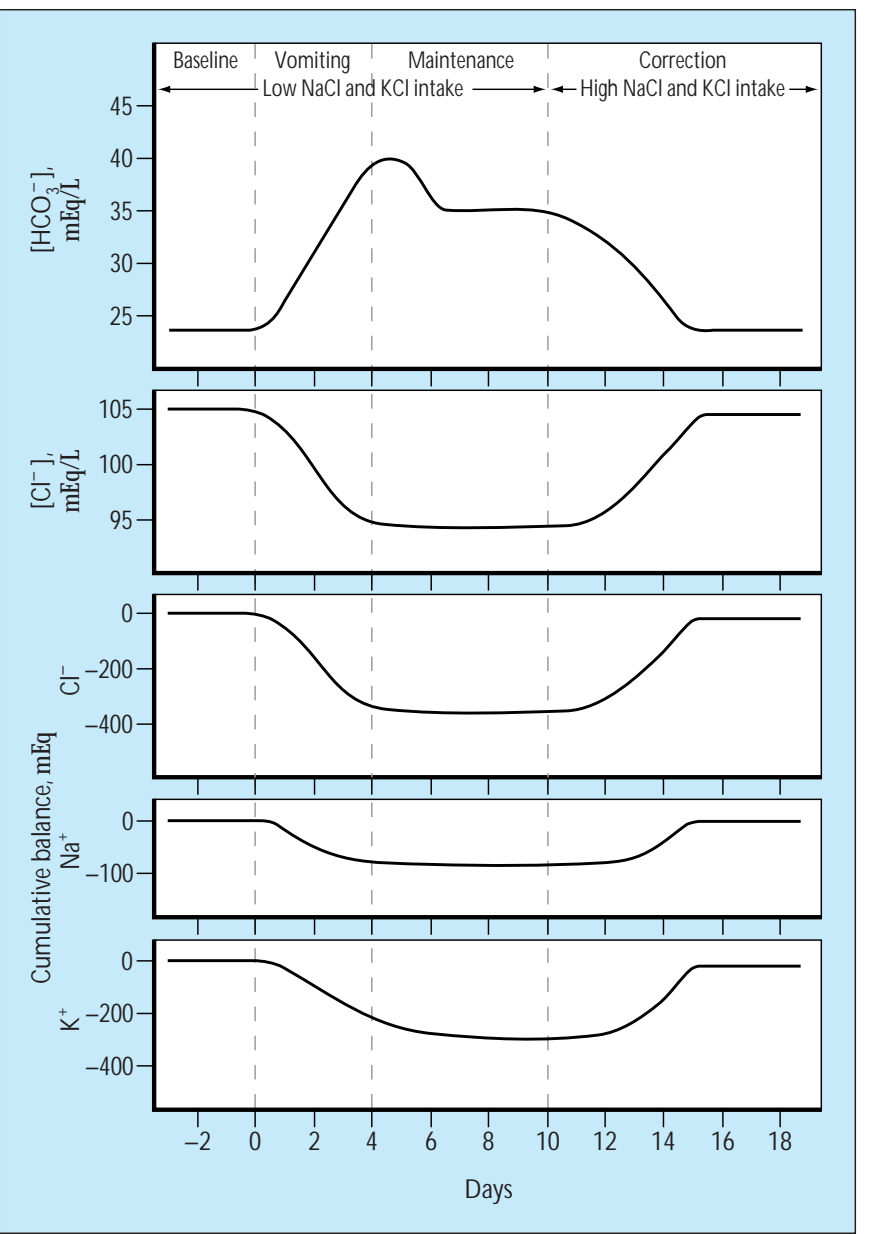

\section{FIGURE 6-32}

Changes in plasma anionic pattern and body electrolyte balance during development, maintenance, and correction of metabolic alkalosis induced by vomiting. Loss of hydrochloric acid from the stomach as a result of vomiting (or gastric drainage) generates the hypochloremic hyperbicarbonatemia characteristic of this disorder. During the generation phase, renal sodium and potassium excretion increases, yielding the deficits depicted here. Renal potassium losses continue in the early days of the maintenance phase.

Subsequently, and as long as the low-chloride diet is continued, a new steady state is achieved in which plasma bicarbonate concentration $\left(\left[\mathrm{HCO}_{3}^{-}\right]\right)$stabilizes at an elevated level, and renal excretion of electrolytes matches intake. Addition of sodium chloride $(\mathrm{N} \mathrm{aCl})$ and potassium chloride $(\mathrm{KCl})$ in the correction phase repairs the electrolyte deficits incurred and normalizes the plasma bicarbonate and chloride concentration ([Cl-]) levels $[22,23]$. 


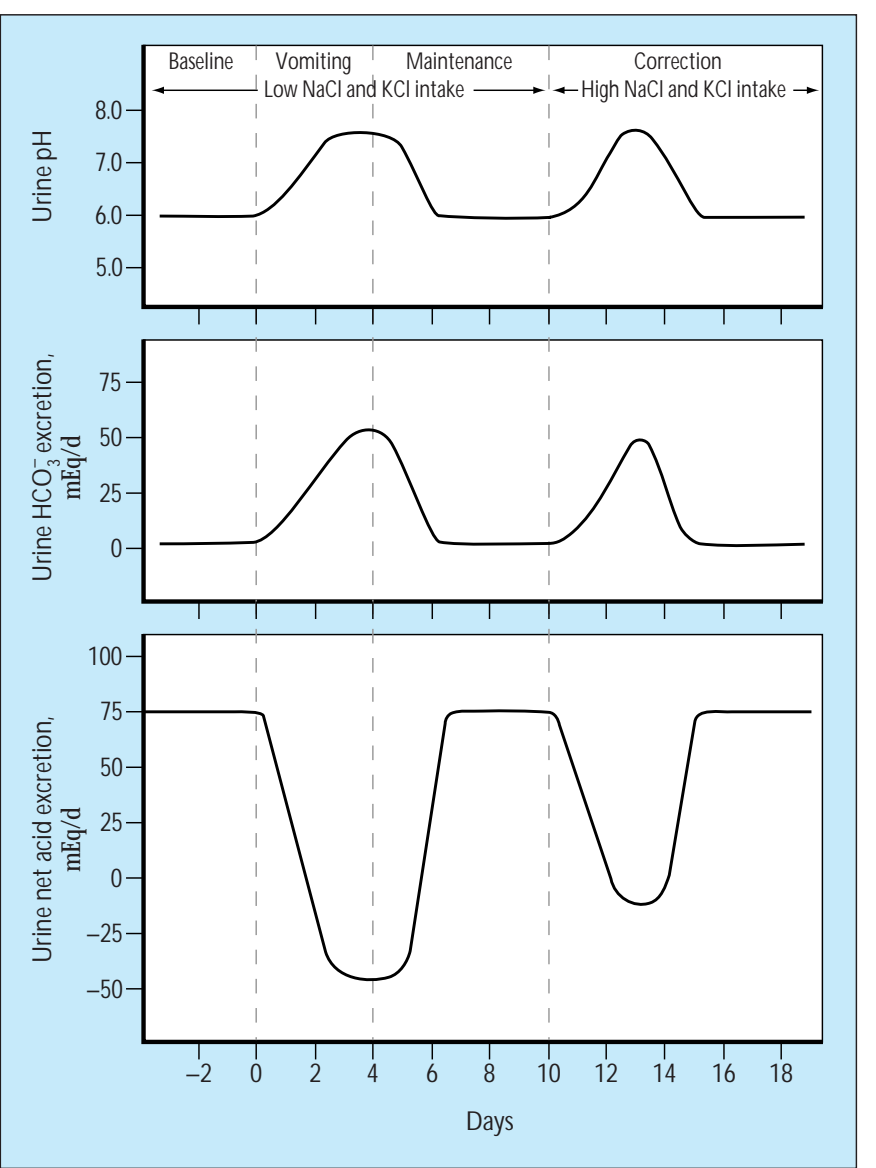

\section{FIGURE 6-33}

Changes in urine acid-base composition during development, maintenance, and correction of vomiting-induced metabolic alkalosis. During acid removal from the stomach as well as early in the phase after vomiting (maintenance), an alkaline urine is excreted as acid excretion is suppressed, and bicarbonate excretion (in the company of sodium and, especially potassium; see Fig. 6-32) is increased, with the net acid excretion being negative (net alkali excretion). This acid-base profile moderates the steady-state level of the resulting alkalosis. In the steady state (late maintenance phase), as all filtered bicarbonate is reclaimed the $\mathrm{pH}$ of urine becomes acidic, and the net acid excretion returns to baseline. Provision of sodium chloride $(\mathrm{NaCl})$ and potassium chloride $(\mathrm{KCl})$ in the correction phase alkalinizes the urine and suppresses the net acid excretion, as bicarbonaturia in the company of exogenous cations (sodium and potassium) supervenes $[22,23]$. $\mathrm{HCO}_{3}^{-}$-bicarbonate ion.

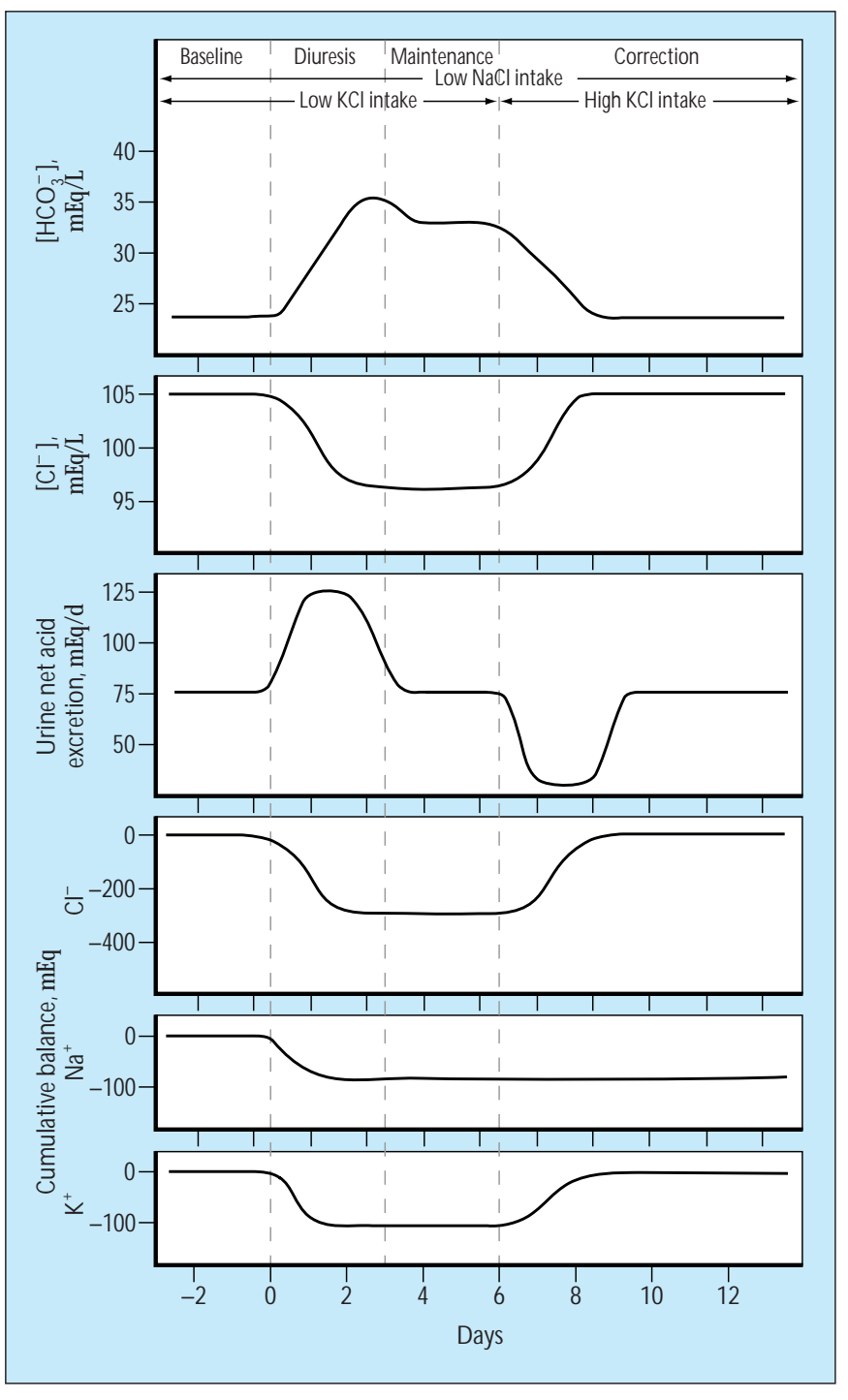

\section{FIGURE 6-34}

Changes in plasma anionic pattern, net acid excretion, and body electrolyte balance during development, maintenance, and correction of diuretic-induced metabolic alkalosis. Administration of a loop diuretic, such as furosemide, increases urine net acid excretion (largely in the form of ammonium) as well as the renal losses of chloride $\left(\mathrm{Cl}^{-}\right)$, sodium $\left(\mathrm{N} \mathrm{a}^{+}\right)$, and potassium $\left(\mathrm{K}^{+}\right)$. The resulting hyperbicarbonatemia reflects both loss of excess ammonium chloride in the urine and an element of contraction (consequent to diuretic-induced sodium chloride [ $\mathrm{NaCl}$ losses) that limits the space of distribution of bicarbonate. During the phase after diuresis (maintenance), and as long as the low-chloride diet is continued, a new steady state is attained in which the plasma bicarbonate concentration ([ $\left.\left.\mathrm{HCO}_{3}^{-}\right]\right)$remains elevated, urine net acid excretion returns to baseline, and renal excretion of electrolytes matches intake. Addition of potassium chloride $(\mathrm{KCl})$ in the correction phase repairs the chloride and potassium deficits, suppresses net acid excretion, and normalizes the plasma bicarbonate and chloride concentration $\left(\left[\mathrm{Cl}^{-}\right]\right)$levels $[23,24]$. If extracellular fluid volume has become subnormal folllowing diuresis, administration of $\mathrm{N} \mathrm{aCl}$ is also required for repair of the metabolic alkalosis. 


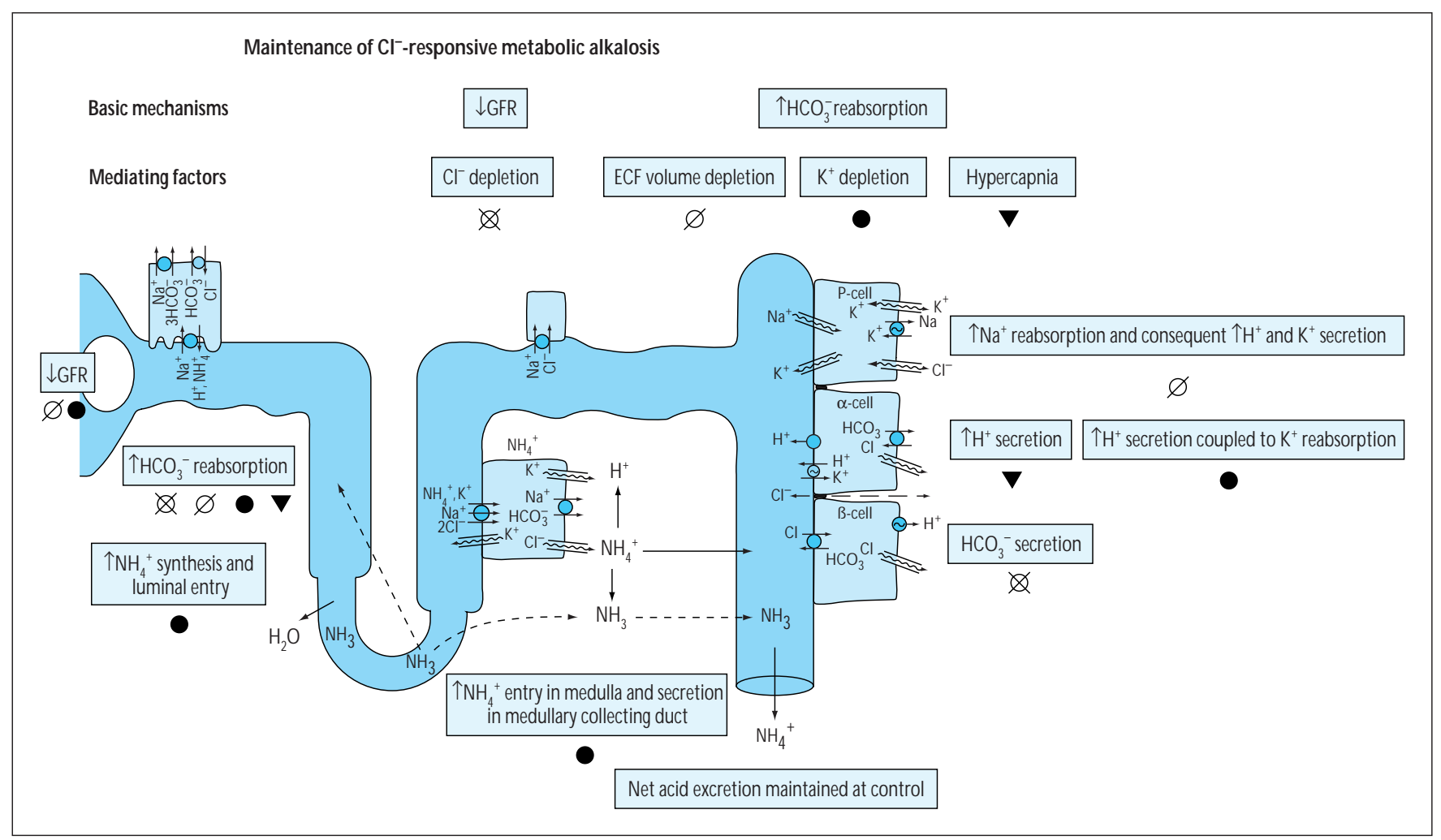

\section{FIGURE 6-35}

$M$ aintenance of chloride-responsive metabolic alkalosis. Increased renal bicarbonate reabsorption frequently coupled with a reduced glomerular filtration rate are the basic mechanisms that maintain chloride-responsive metabolic alkalosis. These mechanisms have been ascribed to three mediating factors: chloride depletion itself, extracellular fluid (ECF) volume depletion, and potassium depletion. Assigning particular roles to each of these factors is a vexing task. N otwithstanding, here depicted is our current understanding of the participation of each of these factors in the nephronal processes that maintain chloride-responsive metabolic alkalosis [22-24]. In addition to these factors, the secondary hypercapnia of metabolic alkalosis contributes importantly to the maintenance of the prevailing hyperbicarbonatemia [25]. 


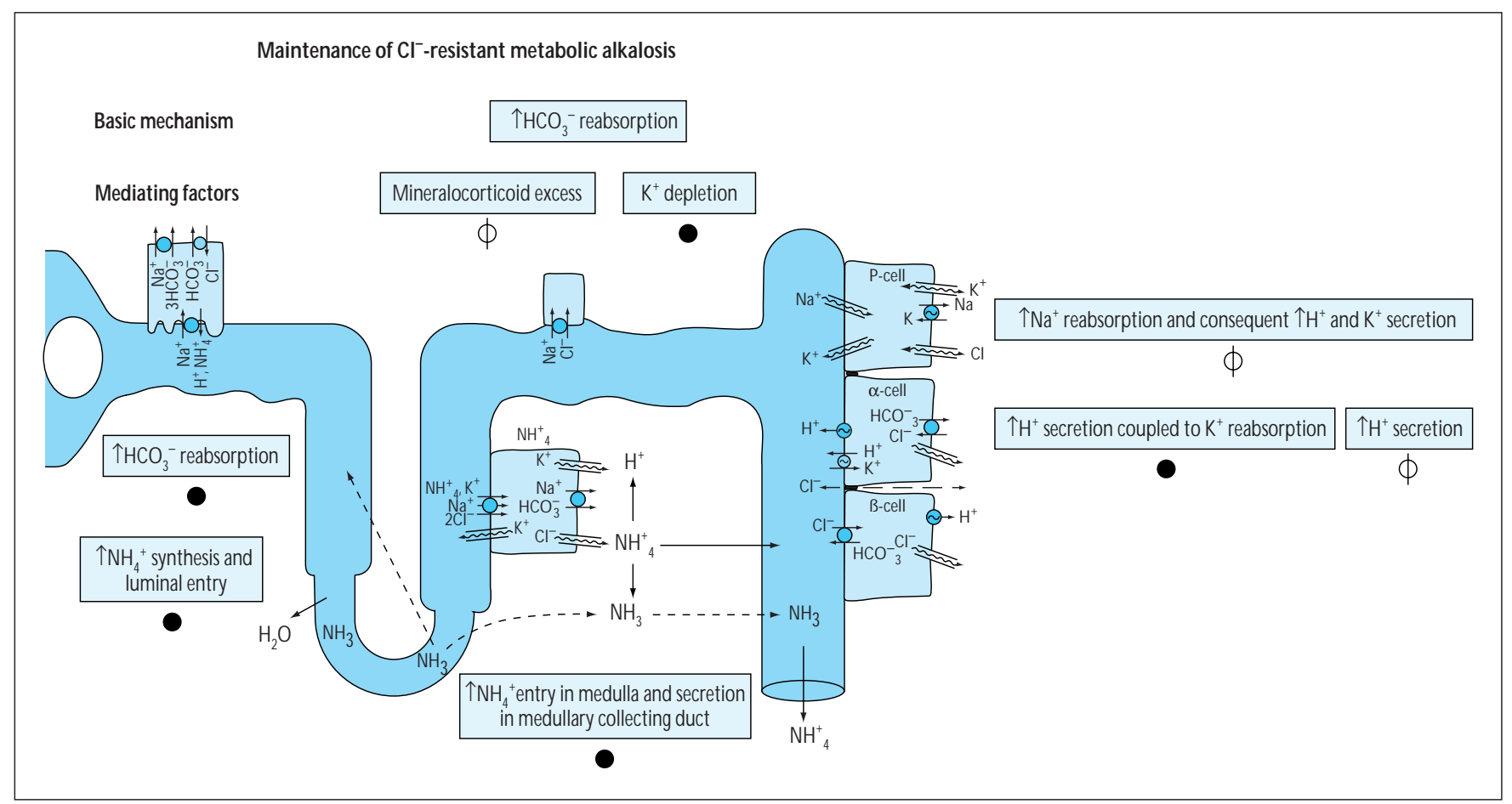

\section{FIGURE 6-36}

M aintenance of chloride-resistant metabolic alkalosis. Increased renal bicarbonate reabsorption is the sole basic mechanism that maintains chloride-resistant metabolic alkalosis. As its name implies, factors independent of chloride intake mediate the height-

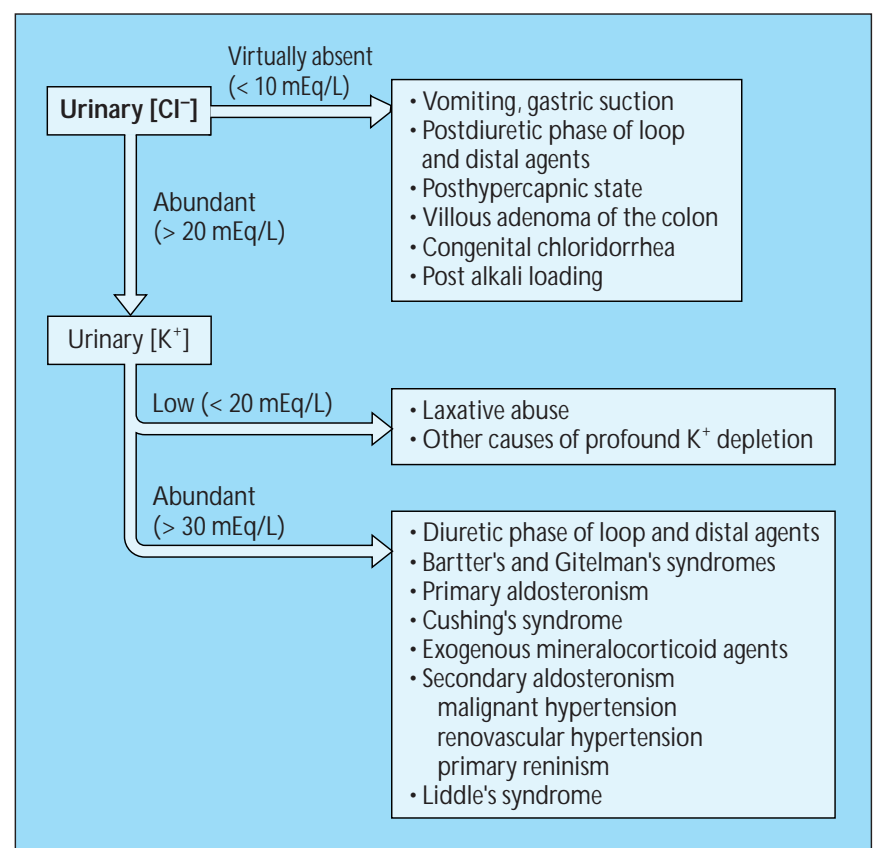

ened bicarbonate reabsorption and include mineralocorticoid excess and potassium depletion. The participation of these factors in the nephronal processes that maintain chloride-resistant metabolic alkalosis is depicted [22-24, 26].

\section{FIGURE 6-37}

Urinary composition in the diagnostic evaluation of metabolic alkalosis. A ssessing the urinary composition can be an important aid in the diagnostic evaluation of metabolic alkalosis. M easurement of urinary chloride ion concentration $\left(\left[\mathrm{Cl}^{-}\right]\right.$) can help distinguish between chlorideresponsive and chlorideresistant metabolic alkalosis. The virtual absence of chloride (urine $\left[\mathrm{Cl}^{-}\right]<10 \mathrm{mEq} / \mathrm{L}$ ) indicates significant chloride depletion. N ote, however, that this test loses its diagnostic significance if performed within several hours of administration of chloruretic diuretics, because these agents promote urinary chloride excretion. M easurement of urinary potassium ion concentration $\left(\left[\mathrm{K}^{+}\right]\right)$provides further diagnostic differentiation. With the exception of the diuretic phase of chloruretic agents, abundance of both urinary chloride and potassium signifies a state of mineralocorticoid excess [22]. 


\section{SIGNS AND SYMPTOMS OF METABOLIC ALKALOSIS}

\begin{tabular}{|c|c|c|c|c|c|}
\hline $\begin{array}{l}\text { Central } \\
\text { Nervous System }\end{array}$ & Cardiovascular System & Respiratory System & Neuromuscular System & Metabolic Effects & $\begin{array}{l}\text { Renal (Associated } \\
\text { Potassium Depletion) }\end{array}$ \\
\hline $\begin{array}{l}\text { Headache } \\
\text { Lethargy } \\
\text { Stupor } \\
\text { Delirium } \\
\text { Tetany } \\
\text { Seizures } \\
\text { Potentiation of hepatic } \\
\text { encephalopathy }\end{array}$ & $\begin{array}{l}\text { Supraventricular and } \\
\text { ventricular arrhythmias } \\
\text { Potentiation of } \\
\text { digitalis toxicity } \\
\text { Positive inotropic } \\
\text { ventricular effect }\end{array}$ & $\begin{array}{l}\text { Hypoventilation with } \\
\text { attendant hypercapnia } \\
\text { and hypoxemia }\end{array}$ & $\begin{array}{l}\text { Chvostek's sign } \\
\text { Trousseau's sign } \\
\text { Weakness (severity } \\
\text { depends on degree of } \\
\text { potassium depletion) }\end{array}$ & $\begin{array}{l}\text { Increased organic acid and } \\
\text { ammonia production } \\
\text { Hypokalemia } \\
\text { Hypocalcemia } \\
\text { Hypomagnesemia } \\
\text { Hypophosphatemia }\end{array}$ & $\begin{array}{l}\text { Polyuria } \\
\text { Polydipsia } \\
\text { Urinary concentration defect } \\
\text { Cortical and medullary } \\
\text { renal cysts }\end{array}$ \\
\hline
\end{tabular}

\section{FIGURE 6-38}

Signs and symptoms of metabolic alkalosis. M ild to moderate metabolic alkalosis usually is accompanied by few if any symptoms, unless potassium depletion is substantial. In contrast, severe metabolic alkalosis ( $\left.\mathrm{HCO}_{3}^{-}\right]>40 \mathrm{mEq} / \mathrm{L}$ ) is usually a symptomatic disorder. Alkalemia, hypokalemia, hypoxemia, hypercapnia, and decreased plasma ionized calcium concentration all contribute to these clinical manifestations. The arrhythmogenic potential of alkalemia is more pronounced in patients with underlying heart disease and is heightened by the almost constant presence of hypokalemia, especially in those patients taking digitalis. Even mild alkalemia can frustrate efforts to wean patients from mechanical ventilation $[23,24]$.

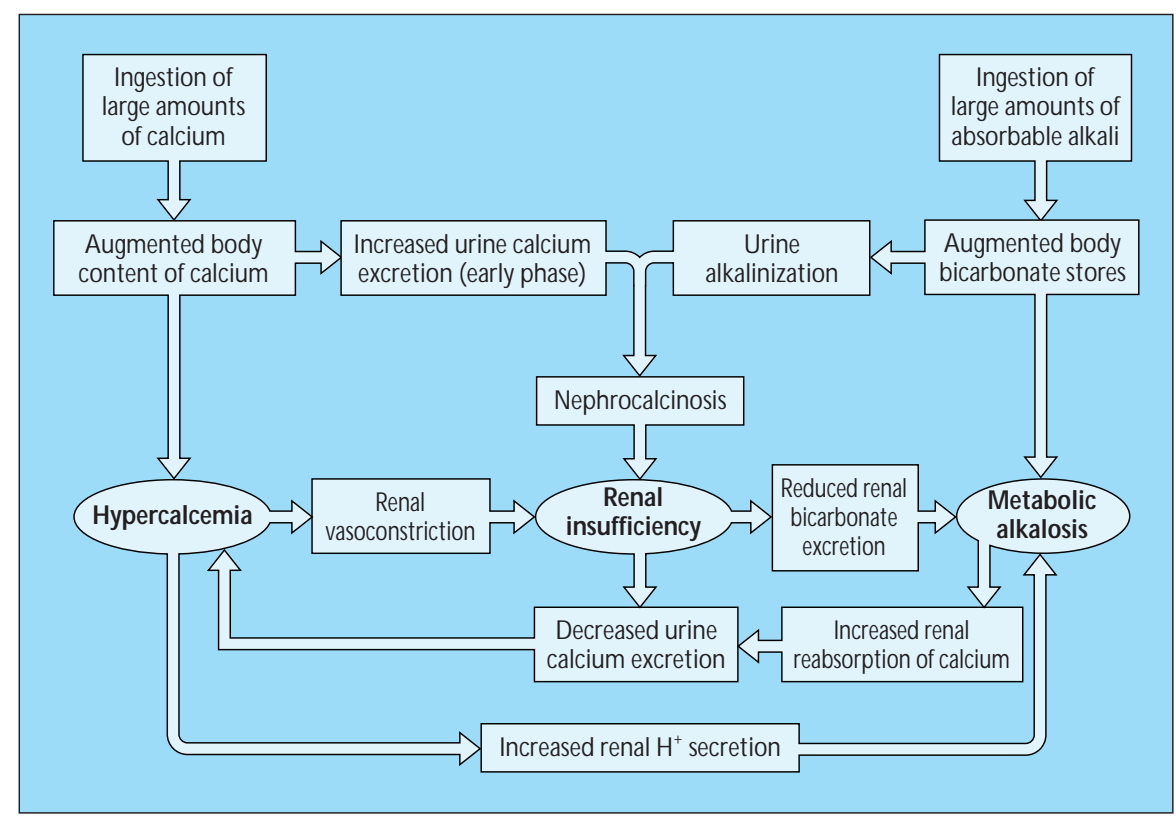

\section{FIGURE 6-39}

Pathophysiology of the milk-alkali syndrome. The milk-alkali syndrome comprises the triad of hypercalcemia, renal insufficiency, and metabolic alkalosis and is caused by the ingestion of large amounts of calcium and absorbable alkali. Although large amounts of milk and absorbable alkali were the culprits in the classic form of the syndrome, its modern version is usually the result of large doses of calcium carbonate alone. Because of recent emphasis on prevention and treatment of osteoporosis with calcium carbonate and the availability of this preparation over the counter, milk-alkali syndrome is currently the third leading cause of hypercalcemia after primary hyperparathyroidism and malignancy. A nother common presentation of the syndrome originates from the current use of calcium carbonate in preference to aluminum as a phosphate binder in patients with chronic renal insufficiency. The critical element in the pathogenesis of the syndrome is the development of hypercalcemia that, in turn, results in renal dysfunction. Generation and maintenance of metabolic alkalosis reflect the combined effects of the large bicarbonate load, renal insufficiency, and hypercalcemia. M etabolic alkalosis contributes to the maintenance of hypercalcemia by increasing tubular calcium reabsorption. Superimposition of an element of volume contraction caused by vomiting, diuretics, or hypercalcemia-induced natriuresis can worsen each one of the three main components of the syndrome. Discontinuation of calcium carbonate coupled with a diet high in sodium chloride or the use of normal saline and furosemide therapy (depending on the severity of the syndrome) results in rapid resolution of hypercalcemia and metabolic alkalosis. Although renal function also improves, in a considerable fraction of patients with the chronic form of the syndrome serum creatinine fails to return to baseline as a result of irreversible structural changes in the kidneys [27]. 


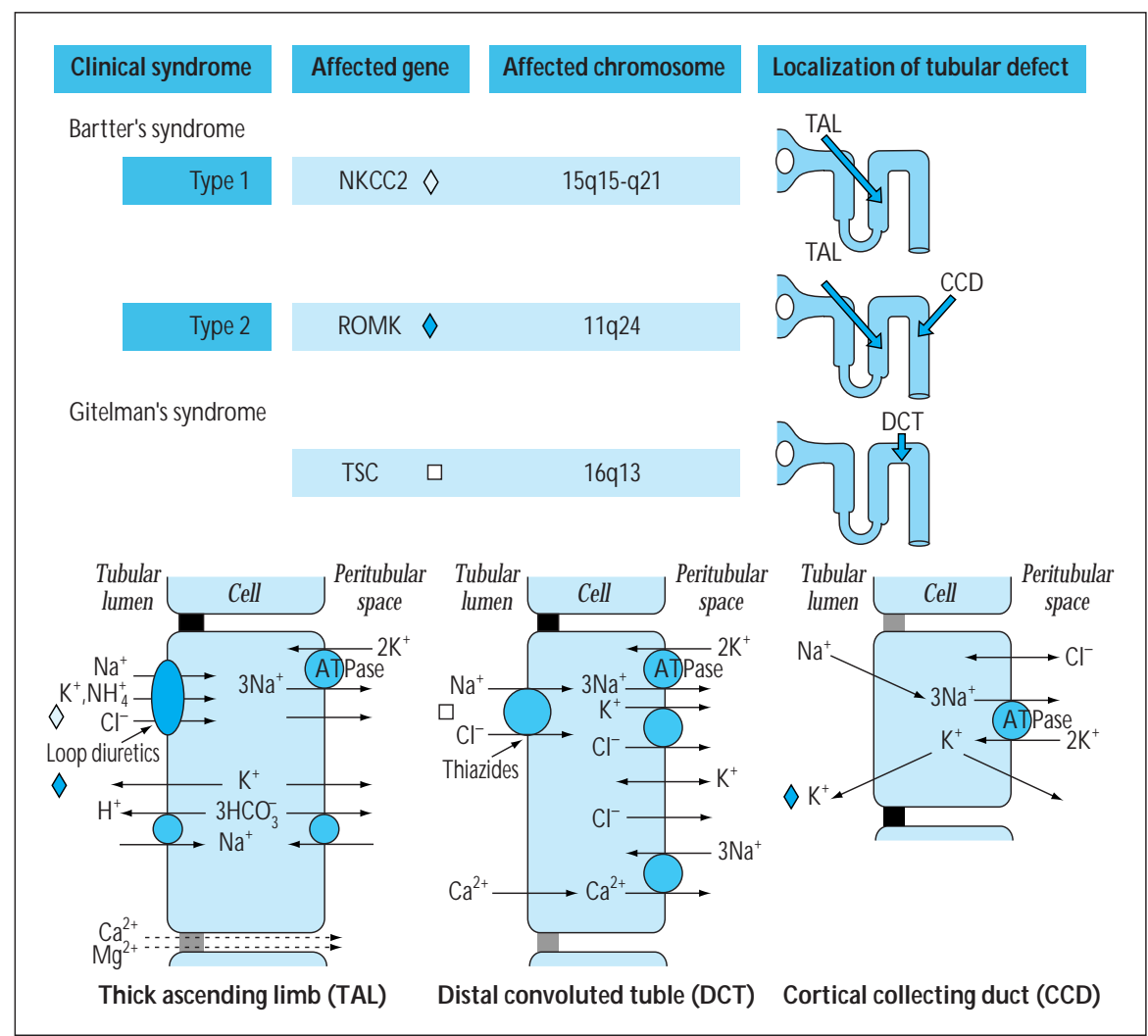

\section{FIGURE 6-40}

Clinical features and molecular basis of tubular defects of Bartter's and Gitelman's syndromes. These rare disorders are characterized by chloride-resistant metabolic alkalosis, renal potassium wasting and hypokalemia, hyperreninemia and hyperplasia of the juxtaglomerular apparatus, hyperaldosteronism, and normotension. Regarding differentiating features, Bartter's syndrome presents early in life, frequently in association with growth and mental retardation. In this syndrome, urinary concentrating ability is usually decreased, polyuria and polydipsia are present, the serum magnesium level is normal, and hypercalciuria and nephrocalcinosis are present. In contrast, Gitelman's syndrome is a milder disease presenting later in life. Patients often are asymptomatic, or they might have intermittent muscle spasms, cramps, or tetany. Urinary concentrating ability is maintained; hypocalciuria, renal magnesium wasting, and hypomagnesemia are almost constant features. O $\mathrm{n}$ the basis of certain of these clinical features, it had been hypothesized that the primary tubular defects in Bartter's and G itelman's syndromes reflect impairment in sodium reabsorption in the thick ascending limb (TAL) of the loop of $\mathrm{H}$ enle and the distal tubule, respectively. This hypothesis has been validated by recent genetic studies [28-31]. As illustrated here, Bartter's syndrome now has been show $n$ to be caused by loss-of-function mutations in the loop diuretic-sensitive sodium-potassium-2 chloride cotransporter (N KCC2) of the TAL (type 1 Bartter's syndrome) [28] or the apical potassium channel ROMK of the TAL (where it recycles reabsorbed potassium into the lumen for continued operation of the N KCC2 cotransporter) and the cortical collecting duct (where it mediates secretion of potassium by the principal cell) (type 2

Bartter's syndrome) $[29,30]$. On the other hand, Gitelman's syndrome is caused by mutations in the thiazide-sensitive $\mathrm{Na}-\mathrm{Cl}$ cotransporter (TSC) of the distal tubule [31]. $N$ ote that the distal tubule is the major site of active calcium reabsorption. Stimulation of calcium reabsorption at this site is responsible for the hypocalciuric effect of thiazide diuretics. 


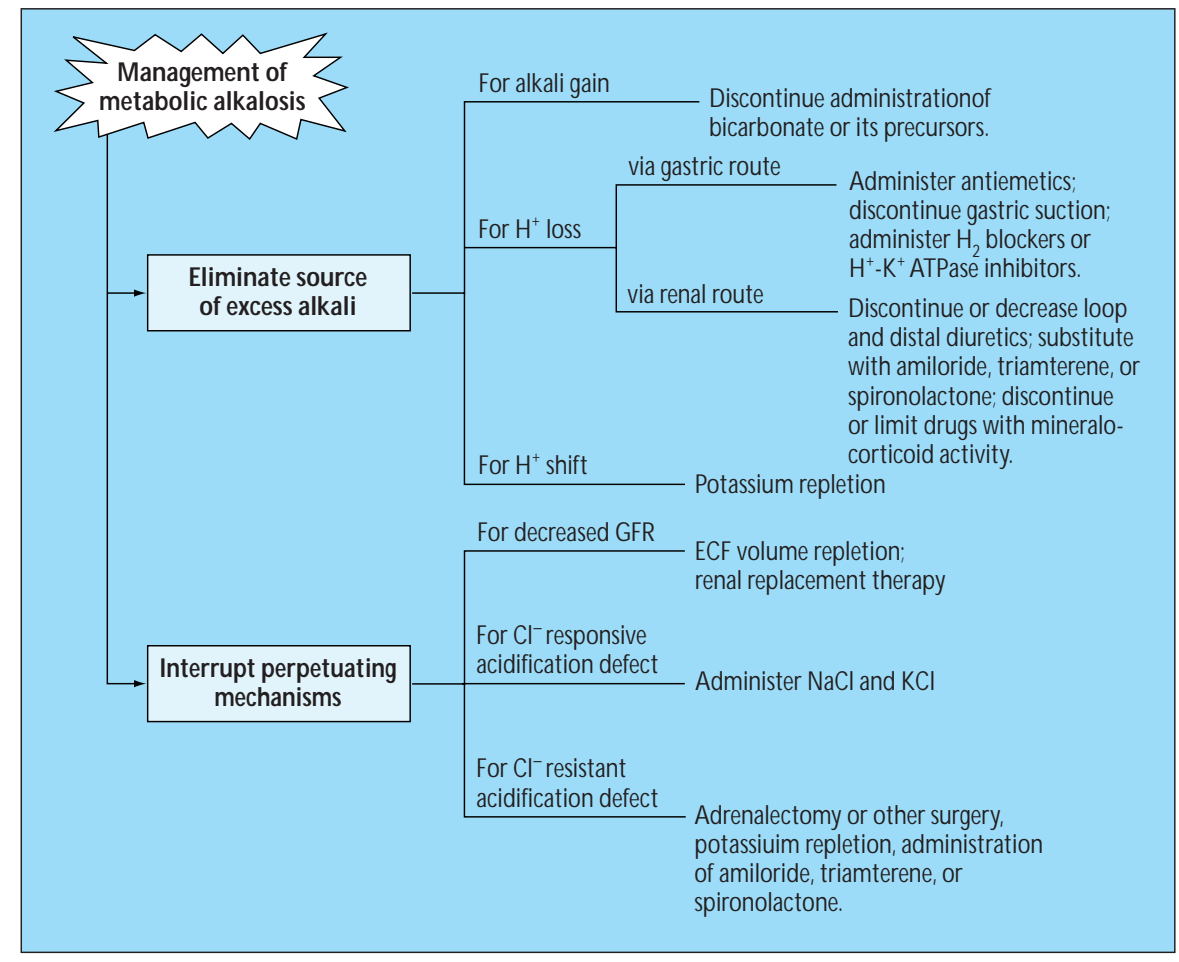

\section{FIGURE 6-41}

$M$ etabolic alkalosis management. Effective management of metabolic alkalosis requires sound understanding of the underlying pathophysiology. Therapeutic efforts should focus on eliminating or moderating the processes that generate the alkali excess and on interrupting the mechanisms that perpetuate the hyperbicarbonatemia. Rarely, when the pace of correction of metabolic alkalosis must be accelerated, acetazolamide or an infusion of hydrochloric acid can be used. Treatment of severe metabolic alkalosis can be particularly challenging in patients with advanced cardiac or renal dysfunction. In such patients, hemodialysis or continuous hemofiltration might be required [1].

\section{References}

1. Adrogué $\mathrm{HJ}, \mathrm{M}$ adias NE: M anagement of life-threatening acid-base disorders. N Engl J Med, 1998, 338:26-34, 107-111.

2. M adias NE, Adrogué $\mathrm{HJ}$ : A cid-base disturbances in pulmonary medicine. In Fluid, Electrolyte, and Acid-Base Disorders. Edited by A rieff Al, Defronzo RA. N ew York: Churchill Livingstone; 1995:223-253.

3. M adias $N E, A$ drogué $H J, H$ orowitz $G L$, et al.: A redefinition of normal acid-base equilibrium in man: carbon dioxide tension as a key determinant of plasma bicarbonate concentration. Kidney Int 1979, 16:612-618.

4. Adrogué HJ, M adias NE: M ixed acid-base disorders. In The Principles and Practice of $\mathrm{N}$ ephrology. Edited by Jacobson $\mathrm{HR}$, Striker GE, Klahr S. St. Louis: M osby-Year Book; 1995:953-962.

5. Krapf R: M echanisms of adaptation to chronic respiratory acidosis in the rabbit proximal tubule. J Clin Invest 1989, 83:890-896.

6. Al-Awqati Q: The cellular renal response to respiratory acid-base disorders. Kidney Int 1985, 28:845-855.

7. Bastani B: Immunocytochemical localization of the vacuolar $\mathrm{H}^{+}$ AT Pase pump in the kidney. $\mathrm{H}$ istol H istopathol 1997, 12:769-779.

8. Teixeira da Silva JC Jr, Perrone RD, Johns CA, M adias N E: Rat kidney band $3 \mathrm{mRN}$ A modulation in chronic respiratory acidosis. A $\mathrm{m} J$ Physiol 1991, 260:F204-F209.

9. Respiratory pump failure: primary hypercapnia (respiratory acidosis). In Respiratory Failure. Edited by Adrogué HJ, Tobin M J. Cambridge, M A: Blackwell Science; 1997:125-134.

10. Krapf R, Beeler I, Hertner D, H ulter H N : Chronic respiratory alkalosis: the effect of sustained hyperventilation on renal regulation of acidbase equilibrium. N Engl J M ed 1991, 324:1394-1401.

11. Hilden SA, Johns CA, M adias NE: Adaptation of rabbit renal cortical $\mathrm{N} \mathrm{a}^{+}-\mathrm{H}^{+}$-exchange activity in chronic hypocapnia. Am J Physiol 1989, 257:F615-F622.
12. Adrogué $\mathrm{HJ}$, Rashad M N, Gorin AB, et al.: Arteriovenous acid-base disparity in circulatory failure: studies on mechanism. Am J Physiol 1989, 257:F1087-F1093.

13. Adrogué $H J$, Rashad $M N$, Gorin $A B$, et al.: Assessing acid-base status in circulatory failure: differences between arterial and central venous blood. N Engl J Med 1989, 320:1312-1316.

14. M adias N E: Lactic acidosis. Kidney Int 1986, 29:752-774.

15. Kraut JA, M adias N E: Lactic acidosis. In Textbook of N ephrology. Edited by M assry SG, Glassock RJ. Baltimore: Williams and Wilkins; 1995:449-457.

16. Hindman BJ : Sodium bicarbonate in the treatment of subtypes of acute lactic acidosis: physiologic considerations. A nesthesiology 1990, 72:1064-1076.

17. AdroguĖ HJ: Diabetic ketoacidosis and hyperosmolar nonketotic syndrome. In Therapy of Renal D iseases and Related Disorders. Edited by Suki W N, M assry SG. Boston: Kluwer Academic Publishers; 1997:233-251.

18. Adrogué HJ, Barrero J, Eknoyan G: Salutary effects of modest fluid replacement in the treatment of adults with diabetic ketoacidosis. JAM A 1989, 262:2108-2113.

19. Bastani B, Gluck SL: N ew insights into the pathogenesis of distal renal tubular acidosis. M iner Electrolyte M etab 1996, 22:396-409.

20. DuBose TD Jr: H yperkalemic hyperchloremic metabolic acidosis: pathophysiologic insights. Kidney Int 1997, 51:591-602.

21. M adias N E, Bossert WH, Adrogué $H J$ : Ventilatory response to chronic metabolic acidosis and alkalosis in the dog. J A ppl Physiol 1984, 56:1640-1646.

22. Gennari FJ: M etabolic alkalosis. In The Principles and Practice of N ephrology. Edited by Jacobson HR, Striker GE, Klahr S. St Louis: M osby-Year Book; 1995:932-942. 


\subsection{8}

23. Sabatini S, Kurtzman N A: M etabolic alkalosis: biochemical mechanisms, pathophysiology, and treatment. In Therapy of Renal Diseases and Related D isorders Edited by Suki W N, M assry SG. Boston: Kluwer Academic Publishers; 1997:189-210.

24. Galla JH, Luke RG: M etabolic alkalosis. In Textbook of N ephrology. Edited by M assry SG, Glassock RJ. Baltimore: Williams \& Wilkins; 1995:469-477.

25. M adias NE, Adrogué $\mathrm{HJ}$, Cohen $\mathrm{J}$ : M aladaptive renal response to secondary hypercapnia in chronic metabolic alkalosis. Am J Physiol 1980, 238:F283-289.

26. H arrington JT, H ulter $\mathrm{HN}$, Cohen JJ, M adias N E: M ineralocorticoidstimulated renal acidification in the dog: the critical role of dietary sodium. Kidney Int 1986, 30:43-48.

27. Beall DP, Scofield RH : M ilk-alkali syndrome associated with calcium carbonate consumption. M edicine 1995, 74:89-96.
28. Simon DB, Karet FE, H amdan JM, et al.: Bartter's syndrome, hypokalaemic alkalosis with hypercalciuria, is caused by mutations in the N a-K-2CI cotransporter N KCC2. N at G enet 1996, 13:183-188.

29. Simon DB, Karet FE, Rodriguez-Soriano J, et al.: Genetic heterogeneity of Bartter's syndrome revealed by mutations in the $\mathrm{K}+$ channel, ROM K. N at G enet 1996, 14:152-156.

30. International Collaborative Study Group for Bartter-like Syndromes. $M$ utations in the gene encoding the inwardly-rectifying renal potassium channel, ROM K, cause the antenatal variant of Bartter syndrome: evidence for genetic heterogeneity. $\mathrm{H}$ um M ol G enet 1997, 6:17-26.

31. Simon DB, N elson-Williams C, et al.: Gitelman's variant of Bartter's syndrome, inherited hypokalaemic alkalosis, is caused by mutations in the thiazide-sensitive N a-Cl cotransporter. N at G enet 1996 , 12:24-30. 